\title{
Procedencia, manufactura y uso de los materiales líticos en el sitio Laguna Cabeza de Buey 2 (centro de los pastizales pampeanos, Buenos Aires) durante el Holoceno medio y tardío
}

(1) Pablo G. Messineo* y Nélida Pal**

\section{Resumen}

En este trabajo se describen los resultados generados a través del estudio tecnomorfológico y funcional de base microscópica de los materiales líticos del sector excavado del sitio Laguna Cabeza de Buey 2. Se integra el conocimiento acerca de las estrategias de obtención, producción y uso de dichos recursos por parte de los grupos cazadores-recolectores bajo dos condiciones paleoambientales diferentes. Durante el Holoceno medio se identifica un ambiente semiárido con la presencia de una laguna somera de agua salada que posibilitó ocupaciones humanas efímeras. Las características tecnológicas, la baja diversidad artefactual y la escasa variabilidad de materiales procesados con los instrumentos, principalmente madera y hueso, sustentan la presencia de sitios de actividades restringidas vinculados con un patrón de alta movilidad. En cambio, para la parte final del Holoceno tardío, el modelo paleoclimático señala condiciones de humedad similares a las actuales, con una vegetación de pastizales más abundante y el establecimiento de un cuerpo semipermanente de agua dulce. En este marco, se registra una ocupación con un mayor grado de intensidad que se sustenta en la mayor cantidad y diversidad artefactual, la amplia gama de sustancias procesadas con los instrumentos (piel, madera, hueso y vegetales no leñosos) y la presencia de cerámica.

Provenance, manufacture and use of lithic materials at Laguna Cabeza de Buey 2 site (Central Pampa grasslands, Buenos Aires) during the Middle and Late Holocene

\begin{abstract}
In this article, we describe the results obtained from the techno-morphological and micro-wear analysis of lithic materials from the excavated sector of Laguna Cabeza de Buey 2 site. Here, we assess data concerning the acquisition, production, and
\end{abstract}

Recibido:

15 de marzo de 2018

Aceptado:

12 de julio de 2018

\section{Palabras clave}

Estudio tecnomorfológico Análisis funcional Movilidad y uso del espacio Cambios ambientales Pastizales pampeanos Holoceno medio y tardío

\footnotetext{
* Investigaciones Arqueológicas y Paleontológicas del Cuaternario Pampeano (INCUAPA), Facultad de Ciencias Sociales, Universidad Nacional del Centro de la Provincia de Buenos Aires (UNICEN) - CONICET. Av. Del Valle 5737 (CP B740oJWI) Olavarría, Buenos Aires, Argentina. E-mail: pmessine@soc.unicen.edu.ar

** Centro Austral de Investigaciones Científicas (CADIC), CONICET. B. Houssay 200 (CP V9410CAB) Ushuaia,

Tierra del Fuego, Argentina. E-mail: nelidapal@yahoo.com.ar
} 
Keywords

Techno-morphological study Micro-wear analysis Mobility and landscape use Environmental changes Pampa grasslands Middle and Late Holocene use strategies of these resources, as developed by hunter-gatherer groups under two different palaeoenvironmental conditions. During the Middle Holocene, we identified a semi-arid environment with the presence of a small, brackish and shallow body of water that permitted ephemeral human occupations. The technological characteristics, the low diversity of typological groups, and types of materials processed by the tools - mainly wood and bone- lends support to the presence of temporary human occupations linked to a high mobility pattern. On the other hand, towards the end of the Late Holocene, the palaeoclimatic model indicates humid conditions similar to the present-day, with a more stable landscape - dunes fixed with grassland vegetation - and the presence of a permanent body of water. In this context, there was a much more intense occupation, reflected in the greater quantity and diversity of tools, the wide range of materials processed with them, including skin, wood, bone and non-woody vegetables, as well as the appearance of pottery.

\section{Introducción}

En los últimos años se han comenzado a efectuar diferentes estudios para tratar de comprender cómo se desarrollaron las ocupaciones humanas en el centro de los pastizales pampeanos, particularmente en el sector donde se localiza la laguna Cabeza de Buey (partido de San Carlos de Bolívar, Buenos Aires). Los trabajos se orientaron a interpretar los procesos adaptativos y los cambios a través del tiempo que experimentaron las poblaciones de cazadores-recolectores en relación con la evolución del paisaje y el ambiente (Messineo et al., 2019). Entre estos estudios se destacan los análisis arqueofaunísticos y tafonómicos efectuados sobre restos de vertebrados (Scheifler, 2018; Scheifler y Messineo, 2016) y tecnomorfológicos de una muestra de materiales líticos del sitio Laguna Cabeza de Buey 2 (Messineo y Scheifler, 2016), la obtención de núcleos de sedimento de la laguna con el fin de estudiar diversos proxies biológicos (Tonello, Messineo, Stutz, Scheifler y Sánchez Vuichard, 2015), el relevamiento sedimentológico-geomorfológico de los perfiles del sitio y de depósitos sedimentarios próximos (Tripaldi, Alonso, Messineo y Salvo Bernárdez, 2018), y la generación de dataciones de ${ }^{14} \mathrm{C}$ y OSL para integrar toda esta información en un marco cronológico y paleoecológico (Messineo y Scheifler, 2016; Messineo et al., 2019).

En este trabajo se describen los resultados generados a través del estudio tecnomorfológico y funcional de base microscópica de los materiales líticos del sector excavado del sitio Laguna Cabeza de Buey 2. La conjunción de ambas líneas metodológicas permite desarrollar un estudio más completo de la tecnología lítica, entendida esta como un fenómeno complejo que involucra factores ambientales y sociales, para acceder a un conocimiento más preciso sobre dichas prácticas tecnológicas por parte de las sociedades cazadoras-recolectoras (Álvarez, 2003; Lemonnier, 1976; Pfaffenberger, 1988). En este sentido, el objetivo principal es integrar el conocimiento acerca de los modos de producción y de uso de los artefactos líticos para los diferentes momentos de ocupación durante el Holoceno medio y tardío. Se pretende comprender la relación entre la tecnología lítica (estrategias de abastecimiento, producción y contexto de uso) y los patrones de subsistencia, movilidad, asentamiento y uso de espacio por parte de los grupos cazadoresrecolectores bajo condiciones ambientales diferentes durante el Holoceno. Asimismo, se examina la información sobre los circuitos de movilidad y las interacciones sociales para entender cuáles fueron los factores vinculados con el abastecimiento y/o intercambio de los materiales líticos por los grupos humanos que ocupaban otros territorios. 


\section{Localización del sitio, características ambientales y procedencias de rocas}

Cabeza de Buey es una laguna que se localiza en la microrregión denominada Depresión del Vallimanca (o Lineamiento del Vallimaca sensu Cingolani, 2005), en la cual se ubican las cuencas de drenaje de los arroyos Las Flores y Vallimanca, así como lagunas permanentes y temporarias localizadas a lo largo de estos ejes fluviales. Particularmente, la laguna se ubica en el sector sur del Campo de Dunas del Centro Pampeano (Figura 1A) correspondiente a una de las unidades del sistema eólico del centro de Argentina (Zárate y Tripaldi, 2012), la cual se clasificó de acuerdo a la naturaleza del depósito, la forma del paisaje dominante y sus características geomorfológico-estructurales. En esta unidad predominan las dunas lineales de 100-130 km de largo y 2-3 km de ancho, con una dirección general nor-noreste, asociadas con dunas parabólicas (Malagnino, 1989). Según varios estudios geológicos, estas dunas se generaron por la acción eólica durante el Pleistoceno final y, en menor medida, por reactivaciones en el Holoceno (Iriondo, 1999; Kruck et al., 2011; Zárate y Tripaldi, 2012).

Este patrón de dunas longitudinales y parabólicas produjo un relieve irregular, 2-5 m, en el cual se generaron numerosas lagunas temporarias y/o permanentes de tamaño variable (entre 0,1 y $7 \mathrm{~km}$ de largo) en las depresiones de interdunas. Cabeza de Buey constituye uno de estos ambientes lacustres (Figura 1B); es una pequeña laguna semipermanente $\left(0,4 \mathrm{~km}^{2} \mathrm{y} \sim 1 \mathrm{~m}\right.$ de profundidad) desarrollada en la deflación de una duna parabólica cuya margen está, actualmente, estabilizada con pastizales y árboles (Messineo et al., 2019). La vegetación de este sector se encuentra dominada actualmente por pastizales de gramíneas tales como Sorghastrum pellitum, Elionurus muticus y varias especies del género Stipa. Otros componentes importantes de la vegetación son Asteraceae, Cyperaceae, Solanaceae, Apiaceae y Chenopodiaceae (León, 1991).

El sitio Laguna Cabeza de Buey 2 se localiza en un ambiente carente de materias primas líticas, por lo cual todas las rocas presentes constituyen recursos no locales. Como ha sido descripto en varios trabajos (Bayón, Flegenheimer y Pupio, 2006; Berón, 2006; Bonomo, 2005; Messineo y Barros, 2015, entre otros), la región pampeana posee una distribución heterogénea de los recursos líticos y solo en ciertos sectores pueden obtenerse rocas para la manufactura de artefactos formatizados. Teniendo esto en consideración, la distancia mínima a las fuentes desde el sitio es de $c a .120 \mathrm{~km}$ para el sector noroccidental del Sistema Serrano de Tandilia (Messineo y Barros, 2015), de $c a .190 \mathrm{~km}$ para el Sistema Serrano de Ventania (Catella, Moirano y Oliva, 2010; Oliva y Moirano, 1997), de ca. 220 para el centro-este de Tandilia (Colombo, 2011), de ca. $300 \mathrm{~km}$ para depósitos secundarios en la costa Atlántica (Bonomo, 2005) y de ca. 400-500 km para los depósitos/afloramientos de subregión Pampa Seca como la Meseta del Fresco (Berón, 2006).

\section{Antecedentes y nuevos datos}

El único antecedente de investigación en esta laguna lo constituye el trabajo realizado por Marcelo Bórmida a fines de la década de 1950 y principios de 1960 bajo la corriente teórica de la Escuela Histórico Cultural de Viena. Este investigador efectuó el estudio de los materiales líticos tallados recuperados en superficie, para los cuales definió dos industrias líticas: Blancagrandense y Bolivarense (Bórmida, s/f). Posteriormente, este mismo autor (Bórmida, 1960) reconoció dos yacimientos arqueológicos en la laguna Cabeza de Buey, el primero en la orilla noroeste y el otro en el sector noreste (Figura $1 \mathrm{~B}$ y C), y realizó excavaciones en el Yacimiento № 2 con el objetivo de corroborar la asignación temporal de las industrias definidas previamente. 

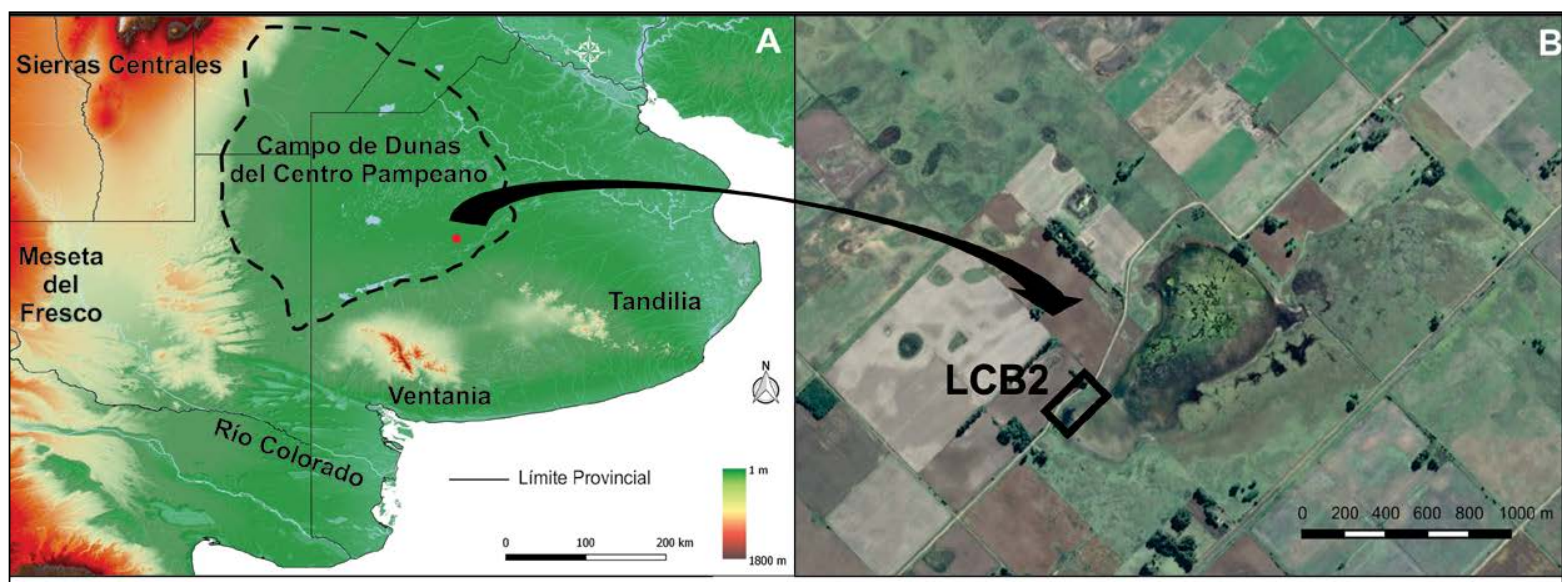

Leyenda

C

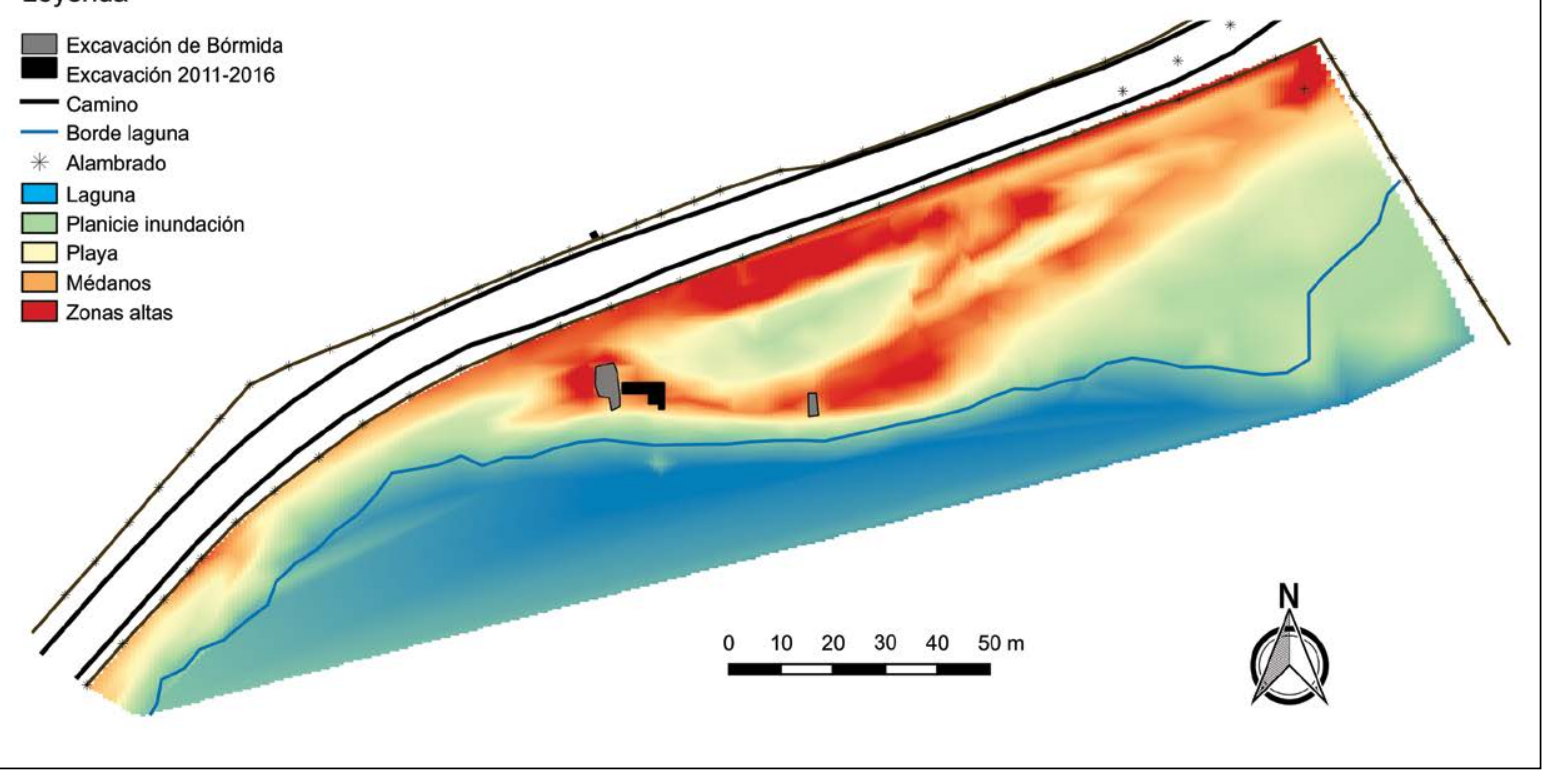

Figura 1. Ubicación del sitio Laguna Cabeza de Buey 2. Referencias: A) localización dentro del Campo de Dunas del Centro Pampeano y localización de las áreas de abastecimiento lítico; $B$ ) ubicación del sitio arqueológico en el ambiente lagunar; $C$ ) relevamiento topográfico donde se localizan las excavaciones.

La mayoría de los hallazgos en estratigrafía, tales como fragmentos de alfarería lisa, ocre, desechos de talla y artefactos líticos asociados a restos esqueletarios de fauna autóctona e introducida, fueron recuperados de la parte superior de la denominada Capa III, la cual, según Bórmida (1960), se formó unos siglos antes y durante la época poscolombina. Los materiales líticos del sitio fueron asignados a una fase primitiva de la industria Bolivarense, la cual arribó a la zona central de la provincia de Buenos Aires a través de la difusión de diversas culturas (Bórmida, 1960, s/f; Madrazo, 1973).

En el marco del proyecto actualmente en curso en el área, a partir del 2011 se comenzó con los trabajos de campo en el sitio Laguna Cabeza de Buey 2 (36¹7’32,5” Sur y $61^{\circ} 11^{\prime} 20,1^{\prime \prime}$ Oeste). Durante seis temporadas de campo se llevó a cabo la excavación de una superficie de $23 \mathrm{~m}^{2}$, localizada de forma adyacente a la efectuada por Bórmida en 1960 (Figura 1C). Esta nueva investigación permitió recuperar diversos elementos culturales, tales como materiales líticos, pigmentos minerales, fragmentos de cerámica, restos óseos y fragmentos de carbón. Cada vestigio mayor a $1 \mathrm{~cm}$ fue registrado tridimensionalmente con una Estación Total para identificar la distribución vertical y 
horizontal de los materiales. Esta distribución y su correspondencia con las unidades sedimentarias identificadas permitieron reconocer cuatro unidades arqueológicas. Tres de estas son asignadas a ocupaciones de cazadores-recolectores en el Holoceno medio y tardío, las cuales se asocian con restos óseos correspondientes a diversas especies autóctonas; mientras que la cuarta se vincula con una ocupación post-Hispánica donde se recobraron ítems modernos y fauna introducida en los niveles superiores de excavación (Messineo y Scheifler, 2016; Scheifler y Messineo, 2016).

\section{Geología, cronología y paleoambiente}

El perfil de la excavación del sitio Laguna Cabeza de Buey 2 y del área circundante sobre la margen sudoeste de la laguna está representado por un registro sedimentario compuesto por cinco unidades (desde el tope a la base U-I, U-II, U-III, U-IV y U-V), las cuales fueron reconocidas tomando en consideración las características sedimentarias y pedogenéticas (Figura 2). Todas las unidades presentan una distribución uniforme de arena fina que indica que la sedimentación estuvo dominada por procesos eólicos asociada a dunas parabólicas en un paisaje con vegetación moderada. Los procesos post-depositacionales, incluidas la bioturbación por raíces y cuevas de animales fosoriales, modificaron este depósito.

En el tope de la secuencia, las U-I y U-II evidencian un proceso pedogenético tenue. La presencia de un enriquecimiento ligero en carbono orgánico sugiere un horizonte A de suelo enterrado en la parte superior de la U-II. Esta unidad posee un mayor contenido de carbonato en relación con la U-I. Estas dos unidades son interpretadas como un suelo acrecional producto de la sedimentación eólica de arena y limo, depósito que fue estabilizado por pedogénesis.

El material arqueológico se recuperó desde la U-I hasta la U-IV, aunque la U-V resultó estéril en términos culturales (Figura 2). En un intento de precisar la cronología de las ocupaciones humanas, se obtuvieron cuatro edades de OSL del depósito y dos dataciones $\mathrm{de}{ }^{14} \mathrm{C}$ sobre muestras arqueológicas. También se tuvo en cuenta la presencia y asociación de diferentes restos arqueológicos en cada unidad. Una de las muestras de OSL de la base de la U-V proporcionó una edad de $12635 \pm 1020$ años AP (Pleistoceno final), mientras que la base de la U-IV se fechó en $6340 \pm 550$ años AP (Holoceno medio). La U-III posee dos dataciones de OSL, una en la base que dio $5330 \pm 410$ años AP (Holoceno medio) y otra en el tope que produjo $2600 \pm 200$ años AP (Holoceno tardío; Messineo et al., 2019).

Con relación a las dos dataciones $d \mathrm{e}^{14} \mathrm{C}$, una fue obtenida sobre un fragmento de carbón de la U-IV y arrojó una edad de $6801 \pm 48$ años AP (7640 \pm 40 años calendáricos AP; AA-104106), mientras que un hueso de guanaco con modificaciones antrópicas de la U-III dio una edad de $4150 \pm 42$ años AP (4700 \pm 90 años calendáricos AP; AA-100947). Estas dos dataciones y los fechados de OSL ubican las ocupaciones de las U-IV y U-III en el Holoceno medio. Por su parte, la ocupación identificada en la U-II se vincula con el Holoceno tardío, posterior a los 2600 años AP, debido a la datación de OSL obtenida para la parte superior de la U-III y a la presencia de cerámica. Por último, en la U-I se registra una ocupación post-Hispánica evidenciada por la presencia de fauna introducida y materiales históricos (Messineo y Scheifler, 2016). El registro de un hiato en la sedimentación entre el Pleistoceno tardío y el Holoceno medio (Messineo et al., 2019) sumado a los procesos post-depositacionales vinculados con la bioturbación (Scheifler, 2018) habrían modificado el depósito sedimentario provocando el desplazamiento horizontal y/o vertical de los materiales arqueológicos. Esto explicaría, además, la inversión de los fechados de OSL y ${ }^{14} \mathrm{C}$ obtenidos para la U-IV.

La reconstrucción paleoclimática para las ocupaciones humanas en la laguna se efectuó a través de varias líneas de evidencia (e.g., polen, palinomorfos no polínicos, 


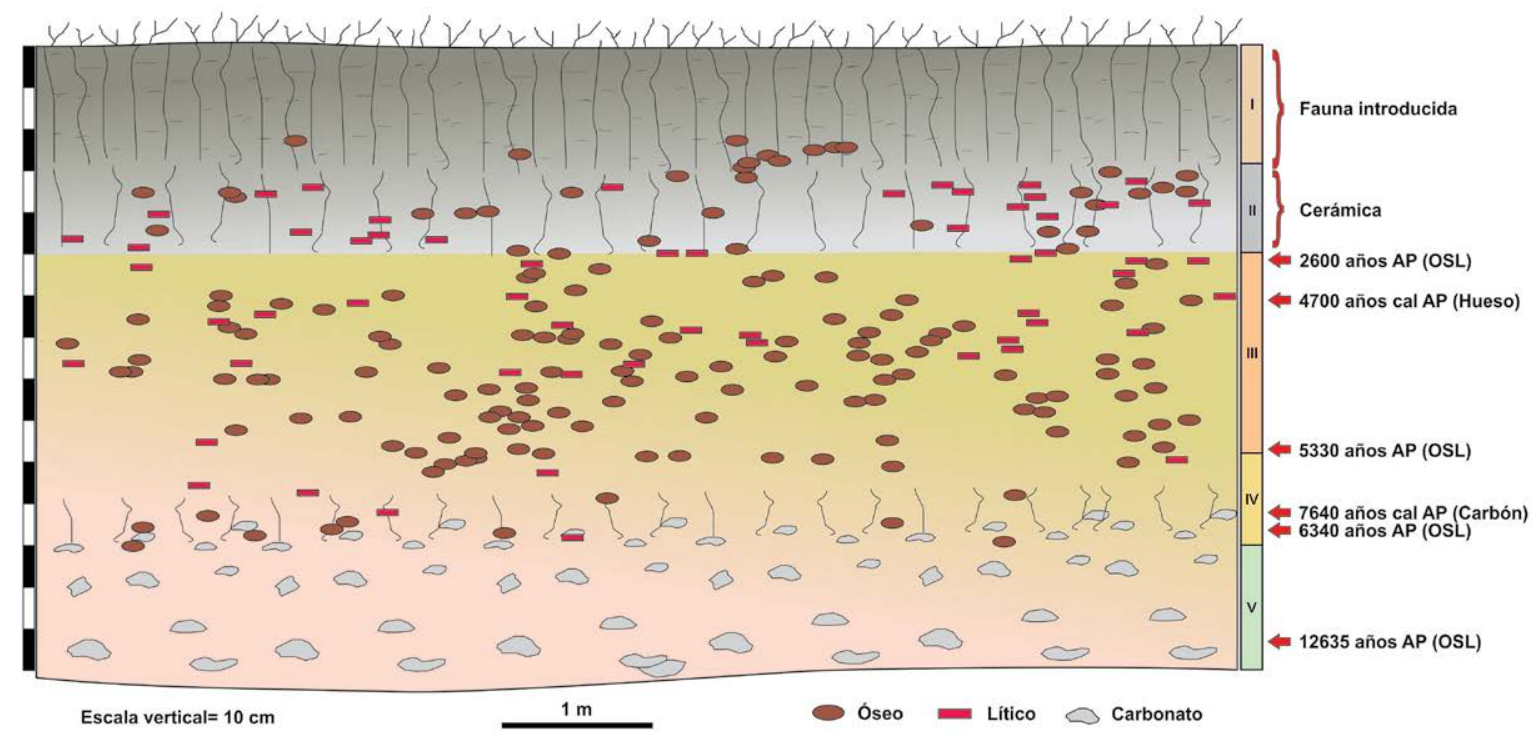

Figura 2. Distribución vertical de los materiales arqueológicos para las diversas unidades identificadas (solo se consideraron las cuadrículas de la pared norte de excavación).

macro-restos vegetales, análisis sedimentológico/geomorfológico, entre otros). Por un lado, durante el Holoceno medio y comienzos del Holoceno tardío (entre ca. 7600 y 2600 años calendáricos AP) las ocupaciones se desarrollaron bajo un clima más seco que el actual (sub-húmedo a semiárido). Por ejemplo, la depositación eólica en las U-IV y U-III sugiere la presencia de mantos de arena. Para este lapso, el registro arqueofaunístico evidencia la presencia de especies restringidas a climas áridossemiáridos y el ensamble de roedores sugiere un mosaico paleoambiental compuesto por dunas y mantos eólicos parcialmente vegetados por pastizales y con cuerpos de agua marginales (Scheifler, 2018). Por su parte, el registro de polen y palinomorfos no polínicos indica la presencia de un cuerpo de agua pequeño, salobre y poco profundo entre 5300 y 1500 años calendáricos AP, en un paisaje inestable de dunas e interdunas donde la comunidad de plantas está pobremente representada (Messineo et al., 2019).

Por otro lado, para momentos avanzados del Holoceno tardío, el marco climático indica condiciones ambientales similares a las actuales. Durante este periodo continúa la sedimentación eólica, pero con un mayor desarrollo de la pedogénesis. La presencia de especies de roedores de linajes tropicales y la desaparición de especies que actualmente se restringen a ambientes áridos/semiáridos indican un aumento de condiciones climáticas húmedas (Scheifler, 2018). El registro de polen y palinomorfos no polínicos revelan que el sistema lagunar de agua dulce estaba bien establecido y con una vegetación regional más abundante a partir de los 1500 años calendáricos AP. Estas condiciones más húmedas están asociadas con un paisaje más estable, con dunas más fijas por la vegetación y con un cuerpo de agua permanente (Messineo et al., 2019).

\section{Materiales y métodos}

Entre los materiales líticos del sitio (Tabla 1) se recuperaron 772 piezas mayores a $5 \mathrm{~mm}$ procedentes tanto del registro tridimensional de la excavación de las 23 cuadrículas $(\mathrm{n}=178)$ como del cernido del sedimento de seis cuadrículas $(n=594)$. En la U-IV se recuperaron 75 ítems, en la U-III 233, en la U-II 376 y en la U-I 88. Las unidades superiores (U-I y U-II) fueron tomadas como un conjunto debido a que el $83 \%$ del material se hallaba en la U-II y la mayoría de los registros tridimensionales muestran que los materiales líticos mayores a 1 
cm se hallaron principalmente en la U-II (Figura 2). Además, los procesos pedogenéticos y la abundancia de la actividad de las raíces fueron más intensos en estas unidades, provocando que la separación de los materiales entre las mismas sea una tarea muy compleja.

El conjunto lítico de cada unidad fue dividido por materias primas, las cuales fueron identificadas a nivel macroscópico, y agrupado en categorías artefactuales amplias (sensu Aschero y Hocsman, 2004) tales como núcleos, artefactos formatizados y desechos de talla (Tabla 1). Para el análisis de los artefactos formatizados y núcleos se siguieron los criterios tecnomorfológicos y los atributos dimensionales propuestos por Aschero $(1975,1983)$ y Aschero y Hocsman (2004), mientras que para los desechos de talla se utilizaron las categorías descriptas en Aschero, Manzi y Gómez (1993-1994) y Bellelli, Guráieb y García (1985-1987).

Para el análisis funcional se estudió una muestra de 22 artefactos formatizados ${ }^{1}$ (17 con filos simples y 5 con filos dobles) y 14 lascas con filos naturales sin rastros complementarios (sólo una lasca poseía filo doble). Los filos naturales analizados de los desechos de talla presentaban longitudes iguales o mayores a $2 \mathrm{~cm}$, con arista recta y sin alteraciones macroscópicas (para una descripción más detallada de los aspectos metodológicos ver Pal, 2012, 2013). En suma, se analizó un total de 42 filos, de los cuales 27 corresponden a filos retocados y 15 a filos naturales de lascas sin formatización secundaria. De la U-IV se analizaron cuatro artefactos formatizados en ortocuarcita (dos con filos dobles) y cinco lascas con filos naturales, de las cuales solo una es de ftanita. En la U-III se analizaron cinco artefactos formatizados y tres lascas con filos naturales en ortocuarcita. Por último, para la U-II/I se estudiaron 13 artefactos formatizados (tres con filos dobles) y seis lascas con filos naturales (una con filo doble). De estos, 11 corresponden a ftanita (nueve artefactos formatizados) y ocho a ortocuarcita (cuatro son artefactos formatizados).

Para el análisis funcional de base microscópica se utilizaron los criterios metodológicos propuestos por Beyries y Rots (2008), Keeley (1980), Kononenco (2011), Lemorini, Stiner, Gopher, Shimelmitz y Barkai (2006), Mansur (1999), Mansur-Franchomme (1986-1990), Pal (2015) y Rots (2012). En cuanto a la identificación de los rastros de uso se utilizó un microscopio metalográfico Olympus BHM con un rango de aumento desde 100X a 500X, priorizándose los 200X de aumento.

\section{Resultados tecno-morfológicos y funcionales}

\section{Unidad IV}

La roca más abundante es la ortocuarcita $(61,3 \%)$ seguida por la ftanita $(34,7 \%)$ y la dolomía silicificada (4\%; Tabla 1), todas procedentes del Sistema Serrano de Tandilia. Entre los artefactos formatizados de ortocuarcita se identificaron dos raederas, un raspador, un artefacto retocado con filo en bisel asimétrico, un artefacto compuesto (raedera + muesca) y dos fragmentos de artefactos formatizados, mientras que en ftanita se reconoció un raspador y un artefacto retocado con filo en bisel asimétrico. En la mayoría de los casos la situación de los lascados sobre el filo fue unifacial directa, salvo por un fragmento de artefacto formatizado con filo bifacial de ortocuarcita, y las formas base corresponden a lascas (indeterminadas, angulares y de arista).

El análisis funcional de los 11 filos (seis retocados y cinco naturales) indica que el $45,4 \%$ presentaba rastros de uso, el $36,4 \%$ no registraba evidencia de uso y el $18,2 \%$ restante no pudo determinarse por presentar alteración (Tabla 2). Los cinco filos usados corresponden a dos artefactos formatizados de ortocuarcita (uno doble y otro compuesto) y a una lasca con filo natural de ftanita. En cuanto a los recursos
1. Se analizó el $51,2 \%$ de los artefactos formatizados por talla (no se incluyen los tres artefactos manufacturados por picado y pulido como una bola de boleadora, un yunque/percutor y un fragmento indeterminado; Tabla 1). El resto no fue analizado porque una parte no ha sido procesada aún ya que se están realizando estudios de ácidos grasos mientras que la otra parte corresponde a fragmentos pequeños de artefactos formatizados con filos menores a $2 \mathrm{~cm}$ y/o con alteraciones macroscópicas. 


\begin{tabular}{|c|c|c|c|c|c|c|c|c|c|}
\hline Unidad & Materia prima & LENT & LFCT & LFST & INDI & $\mathrm{AF}$ & Núcleo & Total & $\%$ \\
\hline \multirow{4}{*}{ IV } & Ortocuarcita & 13 & 7 & 16 & 3 & 7 & - & 46 & 61,3 \\
\hline & Ftanita & 10 & 1 & 10 & 3 & 2 & - & 26 & 34,7 \\
\hline & Dolomía silicificada & 1 & - & 1 & - & - & 1 & 3 & 4,0 \\
\hline & Total & 24 & 8 & 27 & 6 & 9 & 1 & 75 & 100 \\
\hline \multirow{7}{*}{ III } & Ortocuarcita & 48 & 27 & 75 & 15 & 10 & 1 & 176 & 75,5 \\
\hline & Ftanita & 23 & 5 & 12 & 5 & 2 & - & 47 & 20,2 \\
\hline & Dolomía silicificada & - & 1 & - & - & - & 1 & 2 & 0,9 \\
\hline & Chert silíceo & 2 & - & - & - & - & - & 2 & 0,9 \\
\hline & Granitoides & - & - & 2 & - & 3 & - & 5 & 2,1 \\
\hline & Arenisca & - & - & 1 & - & - & - & 1 & 0,4 \\
\hline & Total & 73 & 33 & 90 & 20 & 15 & 2 & 233 & 100 \\
\hline \multirow{9}{*}{ II/I } & Ortocuarcita & 50 & 60 & 129 & 39 & 9 & - & 287 & 61,9 \\
\hline & Ftanita & 47 & 27 & 59 & 10 & 13 & - & 156 & 33,6 \\
\hline & Dolomía silicificada & 1 & 2 & 1 & - & - & - & 4 & 0,9 \\
\hline & Chert silíceo & 6 & 1 & 2 & - & - & - & 9 & 1,9 \\
\hline & Granitoide & 1 & - & - & 3 & - & - & 4 & 0,9 \\
\hline & Arenisca & - & 1 & - & 1 & - & - & 2 & 0,4 \\
\hline & Limolita silicificada & - & - & 1 & - & - & - & 1 & 0,2 \\
\hline & Indeterminable & 1 & - & - & - & - & - & 1 & 0,2 \\
\hline & Total & 106 & 91 & 192 & 53 & 22 & - & 464 & 100 \\
\hline
\end{tabular}

Tabla 1. Distribución de materias primas y categoría artefactual por unidad para el sitio Laguna Cabeza de Buey 2. Referencias. LENT: lascas enteras; LFCT: lasca fracturada con talón; LFST: lasca fracturada sin talón; INDI: desecho indiferenciado; AF: artefacto formatizado.

procesados, se identificó el trabajo de madera $(n=2)$, hueso $(n=1)$ y sustancias indeterminadas $(\mathrm{n}=2)$. Estas últimas se refieren a piezas que posiblemente trabajaron poco tiempo y/o sobre sustancias blandas que no alcanzaron a generar la formación de los típicos pulidos. En cuanto a la cinemática, se registró la combinación de movimientos transversal/longitudinal $(\mathrm{n}=1)$, longitudinal $(\mathrm{n}=1)$, transversal $(\mathrm{n}$ $=2)$ e indeterminado $(n=1)$. Al combinar las variables materia prima, material procesado y cinemática (Tabla 3 ) se puede observar que los artefactos con filos en bisel asimétrico y raederas de ortocuarcita (i.e. filos largos) desbastaron y aserraron madera (Figura $3 \mathrm{E}$ y F), así como material indeterminado, una muesca trabajó hueso de forma transversal (Figura 3D) y una lasca de ftanita con filo natural cortó un material que no pudo ser determinado.

Se identificó un Número Mínimo de Desechos (NMD) de 20 para ortocuarcita, 11 para ftanita y 2 de dolomía silicificada (una de las cuales presentaba modificación térmica). En la Figura 4 se describen los principales resultados de las variables analizadas para los desechos de talla. En relación con el tamaño de las lascas enteras, en ortocuarcita $(\mathrm{n}=13)$ se observa un predominio de las muy pequeñas $(69,2 \%)$, seguidas por las pequeñas $(23,1 \%)$ y mediano pequeñas $(7,7 \%)$. Por su parte, entre los módulos de longitud-anchura se destacan los medianos normales $(38,5 \%)$ y corto anchos $(23,1 \%)$. En ftanita $(\mathrm{n}=10)$ también predominan las lascas muy pequeñas $(80 \%)$ y en muy bajas frecuencias las pequeñas y mediano pequeñas (10\% cada una). Entre los módulos de longitud-anchura predominan los medianos normales (40\%) y cortos muy anchos $(20 \%)$. En cuanto a los tipos de lasca, en ortocuarcita son más frecuentes las de arista $(46,15 \%)$, seguidas por las planas $(23,1 \%)$, angulares $(15,4 \%)$, de reducción directa y dorso natural $(7,7 \%$ cada una). En ftanita se registra un predominio de lascas de reducción directa y de arista ( $40 \%$ cada una), seguidas por las planas y angulares (10\% 

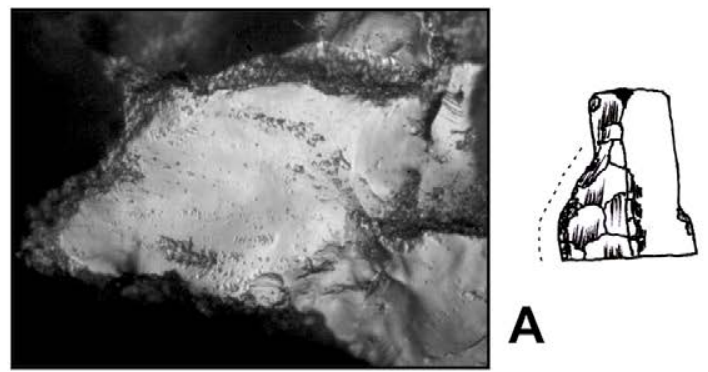

A
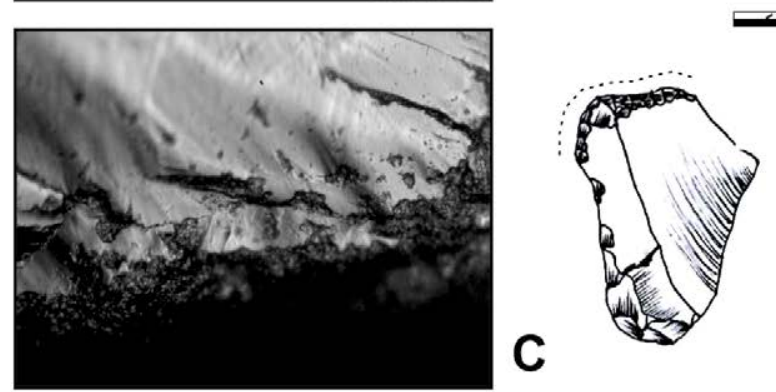

E

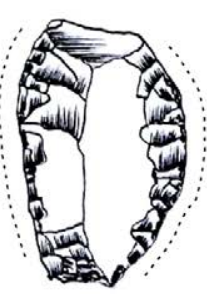

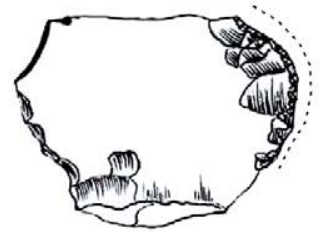

B
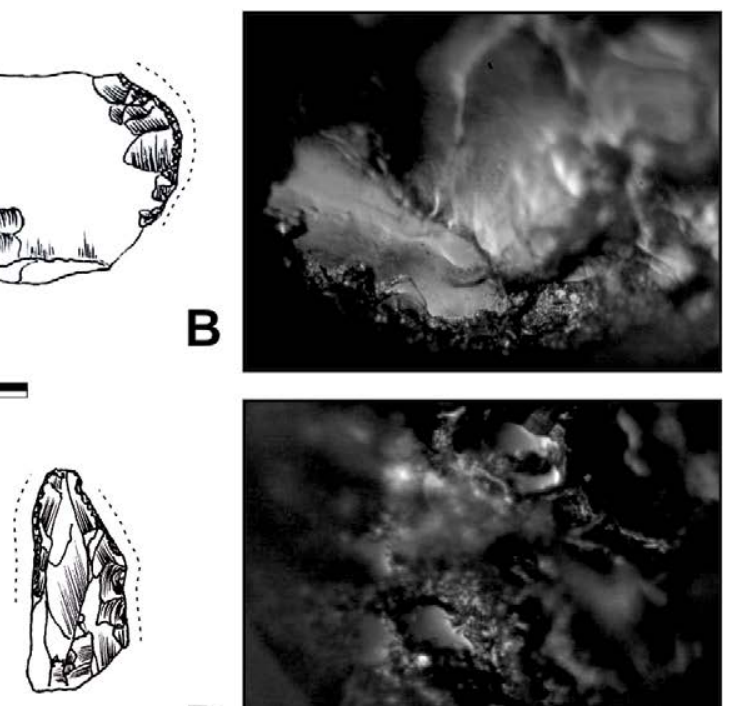

D

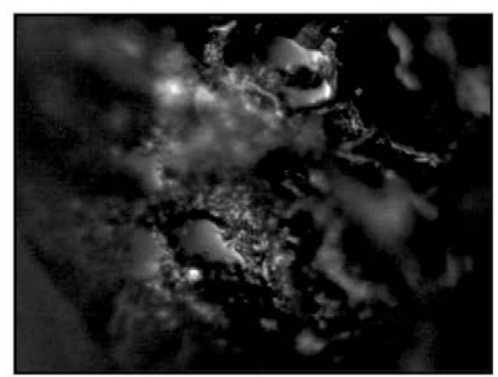

$\mathbf{F}$

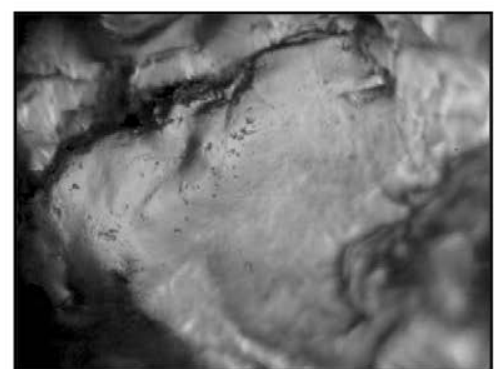

Figura 3. Rastros de uso para las ocupaciones del Holoceno medio. Referencias: A) aserrado/debaste de madera seca en filo izquierdo de ortocuarcita (LCB2.1997, U-III); B) trabajo de sustancia no identificada en filo derecho de ortocuarcita (LCB2.1743, U-III); C) raspado de piel en filo transversal de ortocuarcita (LCB2.959, U-III); D) raspado de hueso en filo izquierdo de ortocuarcita (LCB2.2040, U-IV); E) desbastel aserrado de madera en filo izquierdo de ortocuarcita (LCB2.260, U-IV) y F) aserrado de madera en filo derecho de ortocuarcita (LCB2.260, U-IV).

\begin{tabular}{|l|c|c|c|c|c|c|}
\hline \multirow{2}{*}{ Inferencia funcional } & \multicolumn{2}{|c|}{ Unidad II/I } & \multicolumn{2}{c|}{ Unidad III } & \multicolumn{2}{c|}{ Unidad IV } \\
\cline { 2 - 7 } & $\mathbf{N}$ & $\mathbf{\%}$ & $\mathbf{N}$ & $\mathbf{\%}$ & $\mathbf{N}$ & $\mathbf{\%}$ \\
\hline Usados & 16 & 69,6 & 5 & 62,5 & 5 & 45,4 \\
Sin uso & 3 & 13,0 & 1 & 12,5 & 4 & 36,4 \\
No determinado por alteración & 4 & 17,4 & 2 & 25 & 2 & 18,2 \\
\hline Total & $\mathbf{2 3}$ & $\mathbf{2 3}$ & $\mathbf{8}$ & $\mathbf{1 0 0}$ & $\mathbf{1 1}$ & $\mathbf{1 0 0}$ \\
\hline
\end{tabular}

Tabla 2. Inferencia funcional de los filos por unidades para el sitio Laguna Cabeza de Buey 2.

cada una). Los talones predominantes en ortocuarcita son los lisos (50\%) y filiformes (25\%), mientras que en ftanita los filiformes y puntiformes son mayoría (36,4\% cada uno). La única lasca entera de dolomía silicificada es de arista y con talón facetado (tamaño pequeño y módulo corto anchísimo). Asimismo, sobre esta última roca se halló un fragmento de núcleo del cual se extrajeron lascas.

\section{Unidad III}

Entre las materias primas se observa un predominio de la ortocuarcita $(75,5 \%)$, seguido en porcentajes menores por ftanita $(20,2 \%)$ y otras materias primas como granitoides $(2,1 \%)$, chert silíceo, dolomía silicificada y arenisca $(<1 \%$ cada una; Tabla 
1). Aproximadamente el $99 \%$ de las rocas proceden del Sistema Serrano de Tandilia, mientras que el resto corresponde a afloramientos localizados en la sub-región Pampa Seca (a más de $400 \mathrm{~km}$ del sitio).

Se recuperaron 15 artefactos formatizados, 10 en ortocuarcita (tres raspadores, un artefacto con filo en bisel asimétrico, una punta destacada, una raedera y cuatro fragmentos indeterminados), dos en ftanita (un filo en bisel asimétrico y un fragmento de la base de una punta de proyectil triangular pequeña) y tres en granitoide (una bola de boleadora, un yunque/percutor y un fragmento indeterminado de artefacto modificado por picado, abrasión y pulido). Entre los artefactos formatizados tallados se identificó que en la situación de los lascados sobre el filo predominaba la reducción unifacial directa $(n=7)$, inversa $(n=2)$ y no diferenciada $(n=2)$, mientras que las formas base corresponden a lascas (de arista, angular, indeterminadas y bifacial). El fragmento de punta de proyectil de ftanita (bifacial) se localiza en la parte superior de la UE-III, lo cual indica que podría corresponder a la UE-II ya que este tipo de puntas se ubican cronológicamente en el Holoceno tardío.

El análisis funcional de los ocho filos (cinco retocados y tres naturales) indica que el $62,5 \%$ presentaba rastros de uso, el $25 \%$ no pudo determinarse por la intensidad severa de las alteraciones (lustre de suelo, abrasión sedimentaria y playas de abrasión) y el $12,5 \%$ restante no registraba evidencia de uso (Tabla 2). Los cinco filos usados corresponden en su totalidad a artefactos formatizados de ortocuarcita. En cuanto a los recursos procesados, se identificó el trabajo de madera $(\mathrm{n}=1)$, materiales duros $(\mathrm{n}=2)$, piel $(\mathrm{n}=1)$ y sustancia indeterminada $(\mathrm{n}=1)$. En cuanto a la cinemática, la acción transversal es la más numerosa $(n=2)$ y, en menor cantidad, la longitudinal, la combinación de movimientos longitudinales/transversales e indeterminada ( $\mathrm{n}=1$ cada una). Al combinar las variables materia prima (todos en ortocuarcita), material procesado y cinemática (Tabla 3 ) se puede observar que los filos cortos retocados (en raspador) rasparon piel $(\mathrm{n}=1$; Figura $3 \mathrm{C})$ y material duro $(\mathrm{n}=1)$, mientras que el artefacto con filo en bisel asimétrico aserró material duro (posiblemente hueso) y un fragmento de artefacto con filo en raedera aserró y desbastó madera (Figura 3A). Un filo corto retocado (en raspador) que procesó algún material no pudo identificarse ni la cinemática ni la sustancia (Figura 3B).

El NMD es de 106 (75 de ortocuarcita, 28 de ftanita, dos de chert silíceo y uno de dolomía silicificada). En la Figura 4 se describen los principales resultados de las variables analizadas para los desechos de talla. En relación con el tamaño de las lascas enteras, en ortocuarcita $(n=13)$ se observa un predominio de las muy pequeñas $(66,7 \%)$, seguidas por las pequeñas $(27,1 \%)$ y mediano pequeñas $(6,2 \%)$. Por su parte, entre los módulos de longitud-anchura se destacan los medianos normales $(41,7 \%)$, corto anchos $(18,7 \%)$ y medianos alargados $(14,6 \%)$. En ftanita $(n=23)$ también predominan las lascas muy pequeñas $(82,6 \%)$ y en muy baja frecuencia se presentan las mediano pequeñas $(13 \%)$ y pequeñas $(4,4 \%)$. Entre los módulos de longitud-anchura se destacan los medianos normales $(60,9 \%)$ y los laminares normales $(17,4 \%)$. En cuanto a los tipos de lasca, en ortocuarcita son más frecuentes las de arista $(37,5 \%)$, seguidas por las de reducción directa $(22,9 \%)$, angulares $(16,7 \%)$ y adelgazamiento bifacial $(10,4 \%)$. En ftanita se registra principalmente lascas de arista $(34,8 \%)$ y de reducción directa $(26,1 \%)$, seguidas por las angulares $(16,7 \%)$, las planas y de adelgazamiento bifacial ( $8,7 \%$ cada una). Los talones predominantes en ortocuarcita son los lisos (57,3\%), seguidos por los filiformes y puntiformes $(13,3 \%$ cada uno), mientras que en ftanita prevalecen los lisos $(43,9 \%)$, filiformes $(32,1 \%)$ y puntiformes (17,9\%). Las dos lascas enteras de chert silíceo son angulares y poseen talones liso y diedro (tamaños pequeños y módulos normales). Entre los núcleos, se identificó uno bipolar en ortocuarcita y un fragmento de núcleo de lascas en dolomía silicificada modificado térmicamente. 

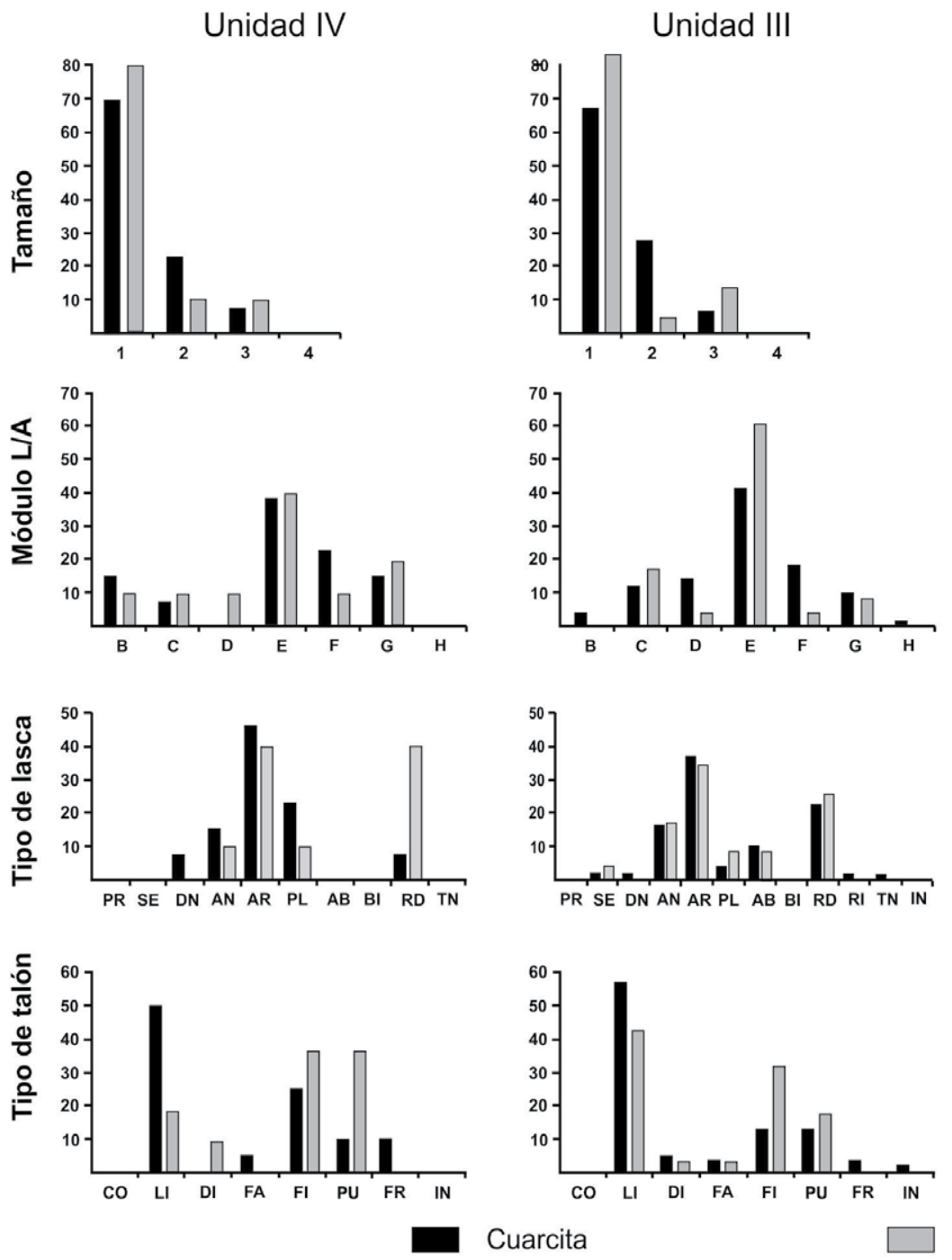

Unidad II/I
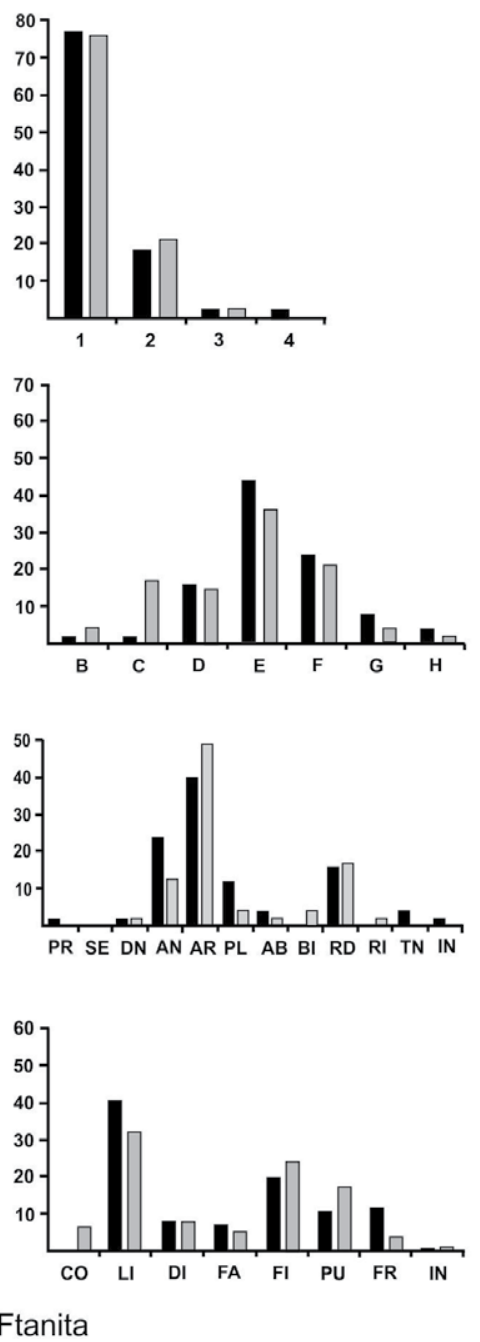

Figura 4. Variables tecnomorfológicas de los desechos de talla. Referencias. 1: muy pequeño; 2: pequeño; 3: mediano pequeño; 4: mediano grande; $B$ : laminar angosto; C: laminar normal; D: mediano alargado; $E$ : mediano normal; $F$ : corto ancho; G: corto muy ancho; $H$ : corto anchísimo; PR: primaria; SE: secundaria; DN: dorso natural; AN: angular; AR: de arista; AB: adelgazamiento bifacial; BI: bipolar; PL: plana; RD: reducción directa; RI: reducción inversa; FN: flanco de núcleo; TN: tableta de núcleo; IN: indiferenciada; CO: cortical; LI: liso; DI: diedro; FA: facetado; FI: filiforme; PU: puntiforme; FR: fracturado; IN: indiferenciado.

\section{Unidad Estratigráfica II/I}

Se observa un predominio de la ortocuarcita $(61,9 \%)$, seguido por la ftanita $(33,6 \%)$ $y$, en porcentajes menores, otras materias primas, tales como chert silíceo $(1,9 \%)$, granitoides y dolomía silicificada ( $0,9 \%$ cada uno), arenisca $(0,4 \%)$, limolita silicificada e indeterminada ( $0,2 \%$ cada uno; Tabla 1$)$. Aproximadamente el $98 \%$ de las rocas proceden del Sistema Serrano de Tandilia, mientras que el resto corresponde a afloramientos localizados en la sub-región Pampa Seca y en las Sierras de Ventania (a ca. $190 \mathrm{~km}$ del sitio).

En este conjunto se recuperaron 22 artefactos formatizados, de los cuales 13 son de ftanita y nueve de ortocuarcita. Entre los primeros se identificaron cuatro raspadores, un cuchillo, un perforador, un artefacto con filo en bisel asimétrico, una raclette, una muesca, un artefacto con retoque sumario y tres fragmentos indeterminados. En la situación de los lascados sobre el filo predomina la reducción unifacial directa $(n=9)$ y en un solo caso se observó un filo bifacial, mientras que las formas bases corresponden en su totalidad a 


\begin{tabular}{|l|c|c|c|c|c|c|}
\hline \multirow{2}{*}{ Actividades desarrolladas } & \multicolumn{2}{|c|}{ Unidad II/I } & \multicolumn{2}{c|}{ Unidad III } & \multicolumn{2}{c|}{ Unidad IV } \\
\cline { 2 - 7 } & N & $\%$ & N & $\%$ & N & $\%$ \\
\hline Desbaste madera & 2 & 14,3 & - & - & 1 & 25 \\
Aserrado/desbaste madera & - & - & 1 & 25 & 1 & 25 \\
Raspado piel & 3 & 21,4 & 1 & 25 & - & - \\
Raspado/aserrado piel & 1 & 7,1 & - & - & - & - \\
Corte vegetal no leñoso & 1 & 7,1 & - & - & - & - \\
Raspado hueso & - & - & - & - & 1 & 25 \\
Raspado material duro & - & - & 1 & 25 & - & - \\
Aserrado material duro & - & - & 1 & 25 & - & - \\
Aserrado/raspado material duro & 2 & 14,3 & - & - & - & - \\
Raspado/aserrado material duro & 1 & 7,1 & - & - & - & - \\
Raspado material blando & 3 & 21,4 & - & - & - & - \\
Raspado material indeterminado & 1 & 7,1 & - & - & - & - \\
Corte material indeterminado & - & - & - & - & 1 & 25 \\
\hline Total & $\mathbf{1 4}$ & 100 & $\mathbf{4}$ & 100 & 4 & 100 \\
\hline
\end{tabular}

Tabla 3. Procesos productivos identificados en el sitio Laguna Cabeza de Buey 2.

lascas (angular, de arista, de dorso natural e indeterminada). En ortocuarcita se reconoció un artefacto compuesto (filo en raedera + filo en raspador), una raedera, un raspador, un artefacto con retoque sumario, un percutor y cuatro fragmentos indiferenciados de artefactos formatizados. Predomina la reducción unifacial directa en los filos $(n=5)$, bifacial $(\mathrm{n}=2)$ y no diferenciada $(\mathrm{n}=1)$, mientras que las formas base corresponden a lascas (angulares, indeterminables y bipolares) y posiblemente a un núcleo.

El análisis funcional de los 23 filos (16 retocados y siete naturales) indica que el 69,6\% presentaba rastros de uso, el 17,4\% no pudo determinarse por presentar alteración (lustre de suelo, abrasión sedimentaria y playas de abrasión) y el 13\% restante de los filos no registraba evidencia de uso (Tabla 2). Los 16 filos usados corresponden a cuatro artefactos formatizados de ortocuarcita (uno con filo doble), cuatro de ftanita (uno con filo doble), dos lascas con filo natural de ortocuarcita (una con filo doble) y dos de ftanita. En cuanto a los recursos procesados, se identificó el trabajo de piel $(\mathrm{n}=$ $4)$, materiales duros $(n=3)$, material blando $(n=3)$, madera $(n=2)$, vegetal $(n=1)$ y sustancia indeterminada $(\mathrm{n}=3)$. En cuanto a la cinemática, la acción transversal es la más numerosa $(\mathrm{n}=9)$, seguida por la combinación de movimientos de longitudinal/ transversal y transversal/longitudinal ( $\mathrm{n}=2$ cada una), la longitudinal $(\mathrm{n}=1)$ y la indeterminada $(\mathrm{n}=2)$.

Al combinar las variables materia prima, material procesado y cinemática (Tabla 3) se puede observar que los filos cortos retocados (en raspador) manufacturados sobre ftanita rasparon piel $(n=1$, Figura $5 A)$ y material blando $(n=1$, Figura $5 B)$, mientras que los tallados en ortocuarcita rasparon piel $(n=1)$ y trabajaron sobre material duro a partir de la combinación de raspado y aserrado $(\mathrm{n}=1)$. Por su parte, los filos largos retocados (e.g., raedera, cuchillo y artefacto con filo en bisel asimétrico) de ortocuarcita rasparon madera $(n=1$; Figura $5 E)$, rasparon/cortaron piel $(n=1$; Figura $5 \mathrm{~F})$ y aserraron/rasparon material duro $(\mathrm{n}=1)$, mientras que los de ftanita rasparon material blando $(n=1)$ y material indeterminado $(n=1$; Figura $5 \mathrm{G})$. Los filos retocados indeterminados de ftanita desbastaron madera $(\mathrm{n}=1$; Figura $5 \mathrm{C})$ y material indeterminado $(\mathrm{n}=1$; Figura $5 \mathrm{D})$. Los filos naturales de ortocuarcita rasparon piel y material blando $(n=2)$, aserraron y desbastaron material duro $(n=1)$ y trabajaron 

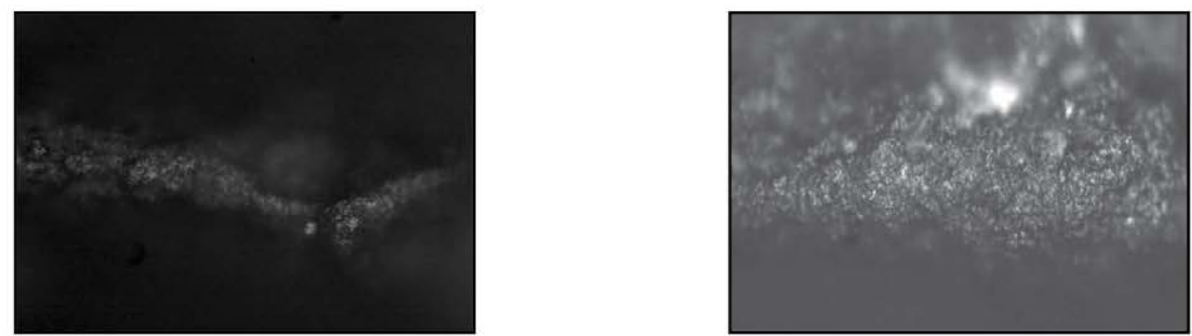

A
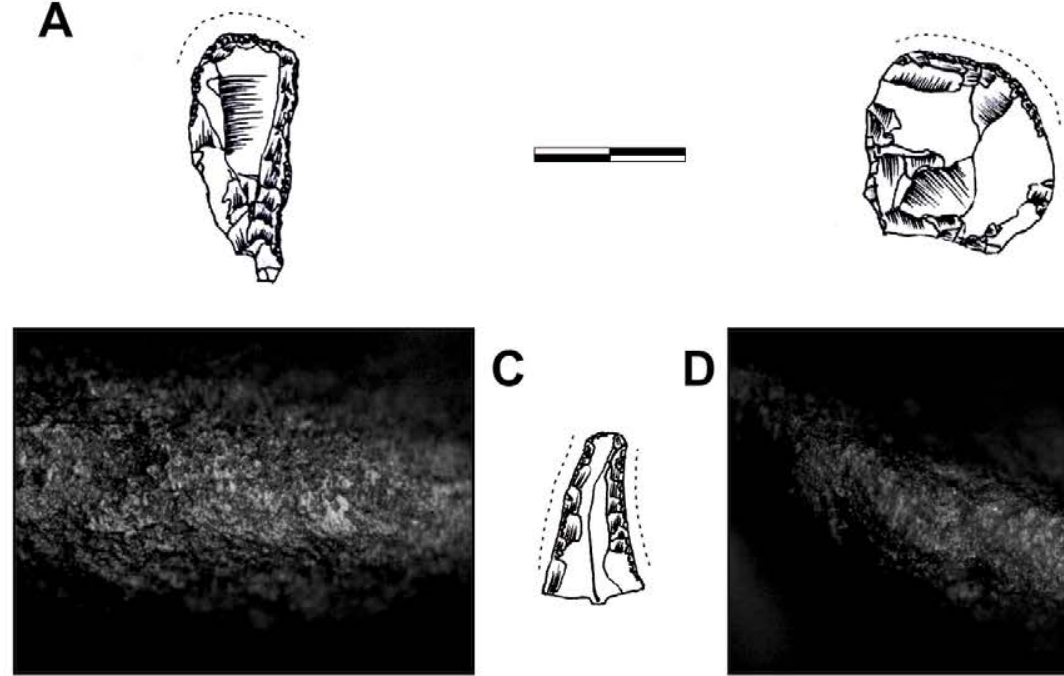

D
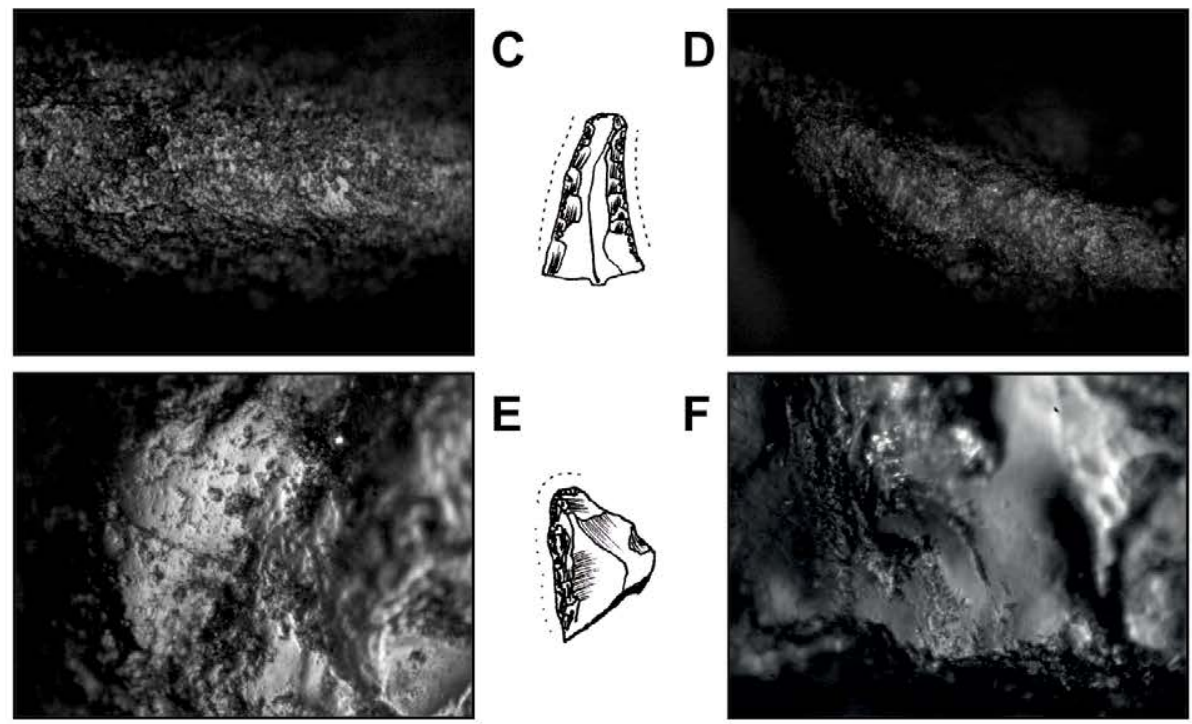

E

$\mathbf{F}$
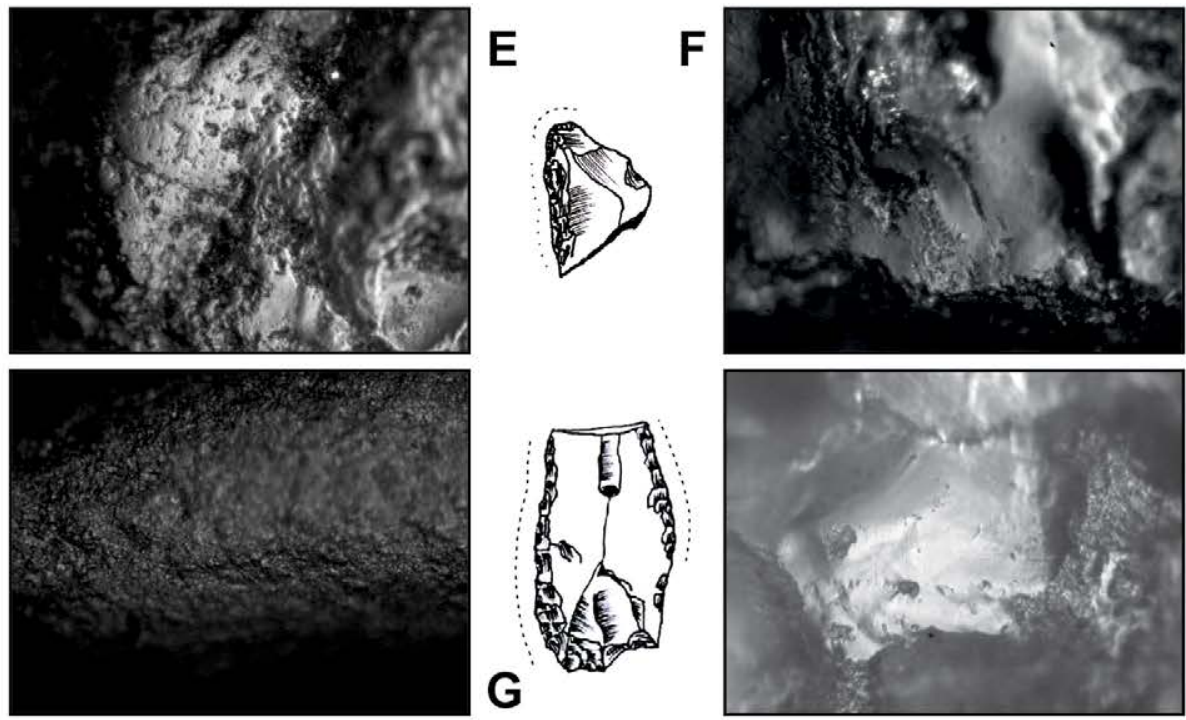

Figura 5. Rastros de uso para la ocupación del Holoceno tardío. Referencias: A) raspado de piel en filo transversal de ftanita (LCB2.1961, U-II); B) raspado material blado en filo transversal de ftanita (LCB2.106, $U-I I)$; C) raspado de madera en filo izquierdo de ftanita (LCB2.504, U-II); D) trabajo de sustancia no determinada en filo derecho de ftanita (LCB2.504. U-II); E) raspado de madera en filo izquierdo de ortocuarcita (LCB2.1822, U-II); F) raspado/aserrado de piel en filo derecho de ortocuarcita (LCB2.1822, U-II) y $G)$ raspado material blando en filo derecho e indeterminable en filo izquierdo de ortocuarcita (LCB2.59, U-II).

material duro con movimiento indeterminado $(\mathrm{n}=1)$. El filo natural de ftanita cortó vegetal no leñoso. Para finalizar, los artefactos con filos dobles se utilizaron con el mismo movimiento o combinado, pero para trabajar diferentes sustancias (e.g., raspado de madera y raspado/corte de piel en ortocuarcita).

El NMD es de 197 (110 de ortocuarcita, 74 de ftanita, siete de chert silíceo, tres de dolomía silicificada, uno de arenisca, uno de granitoide y uno indeterminada). En 
la Figura 4 se describen los principales resultados de las variables analizadas para los desechos de talla. En el tamaño de las lascas enteras de ortocuarcita $(n=50)$, ftanita $(n=47)$ y chert silíceo $(n=6)$ se observa un predominio de los desechos muy pequeños ( $78 \%, 76,6 \%$ y $100 \%$ respectivamente), seguido por los pequeños ( $18 \%$ y $21,3 \%$ respectivamente) y medianos pequeños ( $2 \%$ y $2,1 \%$ respectivamente). Los módulos más frecuentes son medianos normales ( $44 \%, 36,17 \%$ y $60 \%$ respectivamente), seguido por los cortos anchos (24\%, 21,3\% y 16,7\% respectivamente), los medianos alargados en ortocuarcita (16\%) y los laminares en ftanita (17\%). En cuanto a los tipos de lasca, en ortocuarcita son más frecuentes las de arista (40\%), seguidas por las angulares $(24 \%)$, de reducción directa $(16 \%)$ y planas $(12 \%)$. En ftanita se registra un predominio de las lascas de arista $(48,5 \%)$, de reducción directa $(17 \%)$ y angulares $(12,8 \%)$. En ambas rocas se registraron en muy bajos porcentajes lascas externas ( $c a$. $2 \%$ ), de adelgazamiento bifacial (ca. 3\%) y bipolares en ftanita (4,3\%). Los talones más frecuentes en ortocuarcita y ftanita son los lisos (40,9\% y 32,4\% respectivamente), seguido por los filiformes ( $20 \%$ y $24,3 \%$ respectivamente) y puntiformes $(10,9 \%$ y $17,6 \%$ respectivamente). Las lascas enteras de chert silíceo son de reducción directa (50\%), angulares $(33,3 \%)$ y de adelgazamiento bifacial $(16,7 \%)$, con un predominio de los talones lisos $(66,7 \%)$.

\section{Discusión de los resultados e integración con otras líneas de evidencia}

Los resultados alcanzados a través del análisis tecnomorfológico y funcional posibilitan discutir diversos aspectos vinculados con las prácticas tecnológicas, los procesos productivos y las actividades desarrolladas para los diversos momentos de ocupación del sitio. Asimismo, la integración con otras líneas de evidencia, como la explotación de los recursos faunísticos y los cambios ambientales a nivel local (e.g., la dinámica de la laguna, la vegetación y las dunas) permiten indagar sobre los patrones de movilidad, la funcionalidad de las ocupaciones y las formas de ocupar este espacio por parte de los grupos cazadores-recolectores durante el Holoceno medio y tardío.

El primer evento de ocupación reconocido en la laguna se produce en la parte inicial del Holoceno medio (ca. 7600 años calendáricos AP). Con relación al uso de las rocas, se identifican tres materias primas: ortocuarcita del Grupo Sierras Bayas, ftanita y dolomía silicificada, las cuales proceden del Sistema Serrano de Tandilia, principalmente del sector central-oriental (Colombo, 2011) y noroccidental (Messineo y Barros, 2015) de dichas sierras. El predominio absoluto de las rocas de Tandilia muestra que el vector dominante de la circulación humana en el centro de los pastizales pampeanos fue sudeste-noroeste. Esta información concuerda con otros contextos arqueológicos del Holoceno medio del Campo de Dunas del Centro Pampeano, donde las materias primas de Tandilia son predominantes (Messineo, González, Álvarez y Pal, 2018a; Scheifler, Messineo y Antiñir, 2017).

Para esta ocupación se registra la densidad más baja de materiales líticos, tanto para los desechos de talla $\left(4,2\right.$ ítem $\left./ \mathrm{m}^{2}\right)$ como para los artefactos formatizados $(0,39$ ítem/ $\mathrm{m}^{2}$ ), y una baja diversidad de grupos tipológicos para los artefactos formatizados por talla $(\mathrm{n}=4)$. El análisis funcional indica que los artefactos formatizados de ortocuarcita trabajaron materiales duros, como raspar hueso y debastar madera (Figura 6). En tanto la lasca con filo natural de ftanita fue usada pero no se logró especificar el material trabajado ni la cinemática. Los resultados del análisis tecnomorfológico de los desechos de talla sugieren que en el sitio se llevaron a cabo las últimas etapas de la secuencia de reducción, principalmente aquellas vinculadas con la formatización final de instrumentos (e.g., alto porcentaje de lascas internas de muy pequeñas dimensiones) y la reactivación de los filos. 
Todos estos datos sugieren que se efectuaron actividades restringidas en el sitio durante la primera parte del Holoceno medio. Coincidentemente, la evidencia arqueofaunística presentada por Scheifler (2018), como por ejemplo, una baja diversidad de especies procesadas, un escaso número de individuos de estos animales y una alta representación de aquellas unidades de menor rinde económico, sugiere que la ocupación de Laguna Cabeza de Buey 2 correspondería a un locus de actividad específica vinculada con la obtención y el procesamiento primario de animales, principalmente de artiodáctilos como guanaco y venado de las pampas. En este sentido, los escasos instrumentos líticos habrían estado involucrados en estas actividades de procesamiento (raspado de hueso) y, posiblemente, para mantener y/o reparar los sistemas de armas (trabajo sobre madera).

En el segundo evento de ocupación, durante la parte final del Holoceno medio y en los comienzos del Holoceno tardío, se observa una variación en la frecuencia de las materias primas presentes, con un predominio casi exclusivo de la ortocuarcita del Grupos Sierras Bayas en detrimento de la ftanita. Asimismo, se incorporan otras rocas como un granitoide, posiblemente diabasas del sector central del Sistema Serrano de Tandilia (Vecchi, 2016) y chert silíceo cuyas fuentes se localizan en el centro-oeste de la provincia de La Pampa (Carrera Aizpitarte, Berón y Blasi, 2015). Estos datos sugieren que las áreas principales de adquisición de las materias primas siguieron siendo las Sierras de Tandilia, aunque aquí se observa la presencia de una roca procedente desde el oeste, posiblemente como consecuencia de su circulación en el paisaje a través de interacciones con grupos humanos que ocupaban otros sectores de la región pampeana durante este lapso (Carrera Aizpitarte et al., 2015; Messineo et al., 2019; Scheifler et al., 2017).

Para esta ocupación se evidencia un leve aumento en la densidad de artefactos formatizados $\left(0,65 \mathrm{item} / \mathrm{m}^{2}\right)$, desechos de talla $\left(12,5 \mathrm{item} / \mathrm{m}^{2}\right)$ y cantidad de grupos tipológicos, tanto de los artefactos formatizados por talla como por picado y abrasión $(n=6)$. El análisis funcional indica, al igual que la U-IV, que los instrumentos tallados se utilizaron para trabajar principalmente materiales duros, como desbastar/aserrar madera y otros elementos que no pudieron ser determinados (hueso y/o madera), y rasparon piel (Tabla 3; Figura 6). Desde el punto de vista tecnomorfológico, se registra también un predomino de las últimas etapas de reducción lítica (e.g., formatización final y reactivación de filos), aunque en esta unidad, además de una tecnología orientada a la producción de lascas para confeccionar instrumentos, se identificaron lascas de adelgazamiento bifacial. La presencia de este tipo de reducción pone de manifiesto un cambio tecnológico que puede estar asociado a múltiples explicaciones, siendo una de ellas la existencia de una mayor movilidad por parte de los grupos humanos en el paisaje.

El análisis de la fauna (Scheifler y Messineo, 2016) permite sostener que el guanaco siguió siendo el recurso económico más importante, complementado con venado de las pampas y armadillos. Al igual que en la U-IV, el patrón de representación esqueletaria de guanaco registra una frecuencia mayor del esqueleto apendicular, donde las huellas de corte (cuereo, desarticulación y fileteo) se vinculan con el procesamiento de las unidades anatómicas para su posterior transporte (Scheifler, 2018). Los instrumentos líticos recuperados en esta unidad habrían sido utilizados para obtener las presas (e.g., bola de boleadora), para el procesamiento de los recursos animales (raspado de piel y material duro) y, posiblemente, para mantener y/o reparar los sistemas de armas (aserrado y desbaste de madera; Figura 6). Todos estos datos sugieren que esta ocupación de Laguna Cabeza de Buey 2 correspondería también a un locus de actividad específica vinculada con la adquisición y el procesamiento primario de animales por parte de grupos de cazadores-recolectores altamente móviles.

Para el Holoceno tardío, a las materias primas previamente mencionadas (ortocuarcita, ftanita, dolomía silicificada y chert silíceo) se agregan otras rocas de forma escasa como 


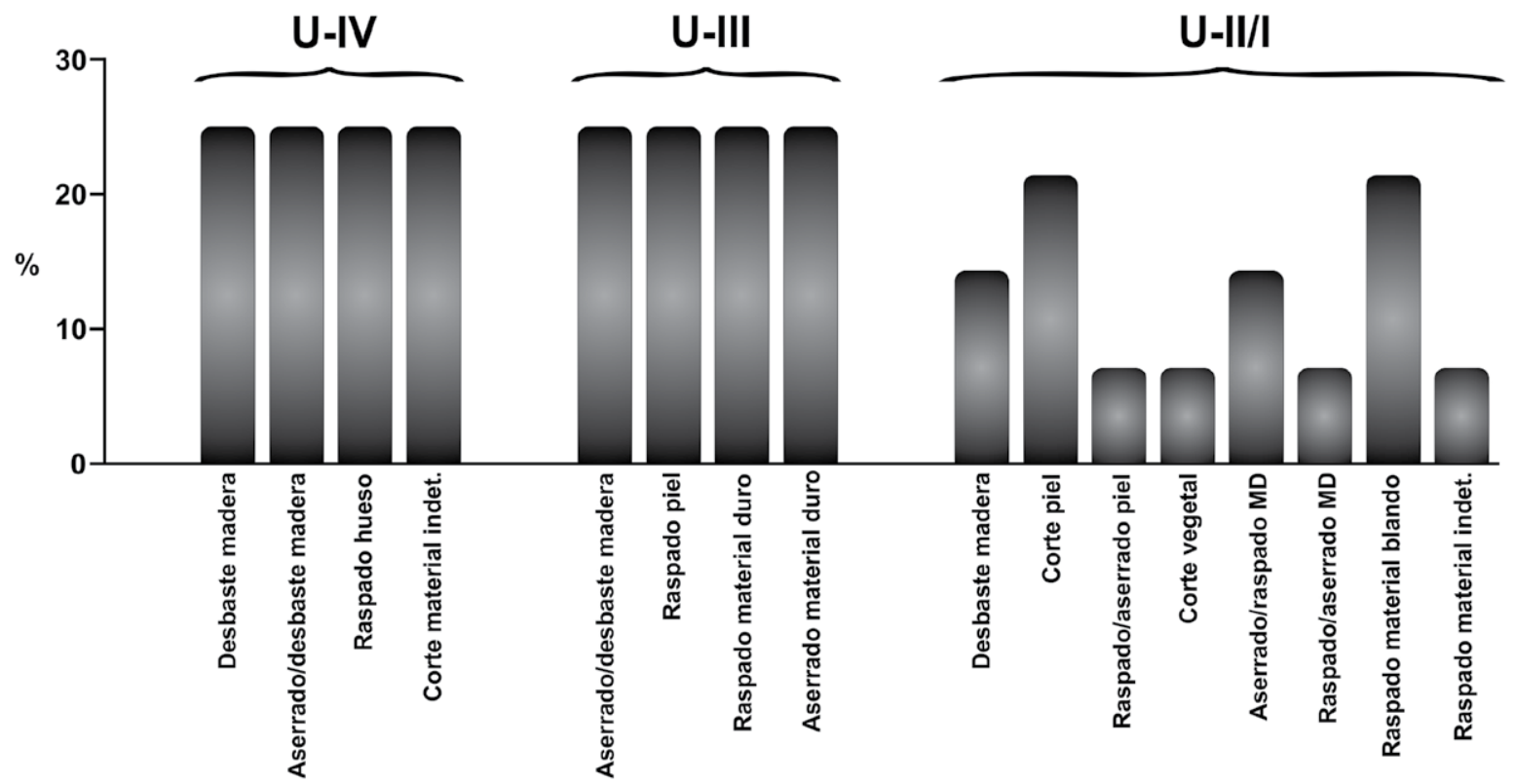

Figura 6. Procesos productivos desarrollados en las distintas unidades que componen Laguna Cabeza de Buey 2.

arenisca y limolita silicificada, esta última procedente posiblemente de Ventania. La presencia de estas rocas en el sitio indica que los circuitos de movilidad y/o interacción entre los grupos humanos continuaron con una predominancia hacia el sudeste (Sierras de Tandilia), aunque se siguen registrando rocas del oeste pampeano y se produce la incorporación, en muy bajas frecuencias, de materias primas procedentes del sector sur de la región pampeana. La elección preferencial de la ortocuarcita en todas las ocupaciones no responde a las distancias a los afloramientos, ya que la ftanita (segunda en importancia) es la roca más próxima a la laguna Cabeza de Buey. Una de las causas principales de la mayor utilización de la ortocuarcita se puede deber, en parte, a que esta roca constituye una de las materias primas de mejor calidad para la talla en los pastizales pampeanos (Bayón, Flegenheimer, Valente y Pupio, 1999). Además, desde el punto de vista funcional, se pueden confeccionar instrumentos con filos versátiles y resistentes (raederas) que permiten procesar diversas sustancias (Leipus, 2016; Leipus y Mansur, 2007; Pal, 2012, 2013).

En esta unidad se registra la mayor densidad de artefactos formatizados $\left(0,96\right.$ ítem $\left./ \mathrm{m}^{2}\right)$ y de desechos de talla $\left(23,5\right.$ ítem $\left./ \mathrm{m}^{2}\right)$ con relación a las unidades del Holoceno medio. Además, el estudio tecnomorfológico evidencia una mayor diversidad de técnicas de talla, como la producción de lascas, el adelgazamiento bifacial y la reducción bipolar. Entre los desechos de talla, aunque siguen predominando las etapas finales de reducción y reactivación de filos, se evidencian otras vinculadas con la obtención y formatización de formas base. Además, se registra un mayor número de grupos tipológicos (raspadores, artefactos compuestos, artefactos con filos en bisel asimétrico, etc.) que, junto con el estudio funcional, da cuenta de una mayor variedad de tareas llevadas a cabo en el sitio, predominando las relacionadas con el procesamiento de recursos animales, como el raspado y aserrado de piel seca con aditivos, el aserrado y raspado de materiales duros (posiblemente hueso) y de materiales blandos de origen animal (carne, tejido y/o tendón). También se destacan los procesos productivos vinculados con el trabajo de elementos vegetales, como el raspado y aserrado de madera y el corte de vegetales no leñosos (Figura 6). La mayor cantidad de actividades se llevó a cabo a partir del uso de artefactos formatizados y de lascas con filos naturales. Sin embargo, el registro arqueofaunístico muestra la continuidad en la explotación de las mismas dos especies 
de artiodáctilos y el patrón de partes de esqueletarias presente es similar al registrado en las ocupaciones del Holoceno medio (Scheifler, 2018).

La presencia de un fragmento de base de punta de proyectil triangular apedunculada pequeña sugiere la utilización del arco y la flecha para obtener a las presas animales. Además, en esta unidad se destaca la presencia de otro tipo de tecnología como es la cerámica. Todos estos datos sugieren que esta ocupación de Laguna Cabeza de Buey 2 correspondería a un locus de actividades múltiples vinculada con la manufactura de artefactos líticos, el procesamiento y consumo de animales (principalmente artiodáctilos), el trabajo de recursos vegetales, madera y cuero, y el uso de contenedores cerámicos para la cocción de los alimentos, entre otros. Posiblemente la presencia de la base de punta de proyectil podría sugerir, también, el recambio de estos instrumentos fracturados en estos contextos residenciales.

Las distintas líneas de evidencia estudiadas permiten discutir algunas de las principales tendencias vinculadas entre la evolución paleoambiental y geomorfológica de la laguna Cabeza de Buey y los cambios en las dinámicas de las ocupaciones humanas. Los resultados obtenidos indican que la laguna fue ocupada durante el Holoceno medio y tardío, aunque se observa una marcada variación en la intensidad del uso de este espacio y la forma de asentarse a través del tiempo.

Para el Holoceno medio, las condiciones climáticas eran más áridas que las actuales (semiárido) y el ambiente presentaba una menor disponibilidad de agua (laguna somera salobre) y dunas activas con escasa cobertura de la vegetación. En este escenario, la evidencia arqueológica sugiere ocupaciones efímeras de poblaciones móviles de cazadores-recolectores que visitaron este espacio cuando se formaban estos pequeños cuerpos de agua, posiblemente a través del forrajeamiento diario (Politis, 2007) y/o por una movilidad logística (Binford, 1980) para explotar los recursos faunísticos. La baja variedad de taxones explotados en las U-IV y U-III (e.g., obtención y procesamiento de artiodáctilos) así como la baja diversidad de grupos tipológicos y materiales procesados sustentan que estas ocupaciones efímeras corresponden a sitios de actividades restringidas. Según Scheifler (2018), la representación de unidades anatómicas y las evidencias de procesamiento responden, principalmente, a las estrategias de transporte de las presas a los espacios de consumo final (asentamientos de actividades múltiples). Es decir, la laguna habría funcionado, dentro de este escenario de mayor aridez, como un locus de extracción y procesamiento de animales por parte de los cazadoresrecolectores. Los materiales líticos identificados sugieren el empleo de una estrategia de aprovisionamiento de los individuos, quienes utilizaron dichos materiales para el desarrollo de actividades restringidas. En este sentido, las ocupaciones de Laguna Cabeza de Buey 2 formaron parte de un sistema de asentamiento mayor en el cual los sitios de actividades múltiples se localizaban en cursos de agua o lagunas que permitían una mayor permanencia de las poblaciones humanas.

Para el Holoceno tardío (últimos 2000/1500 años calendáricos AP), el modelo paleoclimático señala condiciones de humedad similares a las actuales con una vegetación de pastizales más abundante y el establecimiento de un cuerpo de agua dulce con las características que posee hoy la laguna Cabeza de Buey (Messineo et al., 2019). Durante este momento se observa un cambio notorio en la forma de ocupar este ambiente lagunar, ya que es posible pensar que las ocupaciones humanas se dieron más recurrentemente. Esto se sustenta en la mayor cantidad y diversidad artefactual, la amplia gama de actividades efectuadas con los instrumentos y la presencia de cerámica y de rocas con diversas procedencias, entre otros aspectos. El mejoramiento de las condiciones climáticas de este periodo causó el aumento de la disponibilidad de los cuerpos de agua en el paisaje y la laguna Cabeza de Buey pasó a formar parte de un lugar para localizar los asentamientos residenciales. Sin embargo, más allá de la presencia de 
la laguna Cabeza de Buey, esta no parece haber funcionado como un concentrador de las poblaciones humanas como pudo haber sucedido en otros ambientes lagunares del Campo de Dunas del Centro Pampeano, donde los cuerpos de agua poseen dimensiones mayores, son permanentes y albergan una mayor cantidad de recursos animales y vegetales para explotar. En algunos de estos sitios se registra la presencia de indicadores de uso anticipado de estos espacios, como una gran cantidad de artefactos de molienda, escondrijos y entierros humanos (Messineo et al., 2019; Scheifler et al., 2017), ausentes hasta el momento en la laguna Cabeza de Buey.

\section{Conclusiones}

La presencia de rocas procedentes de las Sierras de Tandilia (ortocuarcita y ftanita) para los diversos momentos de ocupación en el Holoceno medio y tardío permite concluir que el principal vector de movilidad de las poblaciones de cazadores-recolectores que ocuparon la laguna fue en sentido sudeste-noroeste. Los cambios tecnológicos observados, la presencia de ciertas rocas minoritarias y la diversidad en los usos de los instrumentos para los diversos momentos de ocupación se efectuaron para resolver diversos problemas vinculados con factores ambientales, económicos y/o sociales. Entre los primeros, las características ambientales diferentes para el Holoceno medio y tardío generó que los grupos humanos implementaran distintos patrones de movilidad, asentamiento y uso del espacio. Esto tuvo incidencia en la forma de adquirir las rocas, en las técnicas de talla, en la producción de ciertos instrumentos y en el uso de los mismos.

Para finalizar, los resultados obtenidos en este artículo aportan información sobre las estrategias de producción (aprovisionamiento y manufactura) y uso de instrumentos líticos confeccionados sobre diferentes rocas durante en el Holoceno medio y tardío. Estos resultados permitieron discutir cómo las modificaciones en la tecnología, la movilidad y el uso del espacio estuvieron vinculadas con los cambios ambientales en dos momentos diferentes. Futuros análisis de otros conjuntos líticos del Campo de Dunas del Centro Pampeano permitirán discutir en mayor profundidad sobre estas $y / u$ otras variables que incidieron en los cambios tecnológicos llevados a cabo por los grupos cazadores-recolectores durante el Holoceno.

\section{Agradecimientos}

Las investigaciones se realizan con el apoyo de la Municipalidad de San Carlos de Bolívar por medio de la colaboración del Sr. Santos Vega. A los estudiantes de Arqueología de la Facultad de Ciencias Sociales (UNICEN) que colaboraron en las tareas de excavación. Las investigaciones en la laguna fueron financiadas por la ANPCYT (PICT 20080430, PICT 2010-1415 y PICT 2014-2070), el CONICET (PIP 2014-0414) y National Geographic Society (Grant \#9773-15). Este artículo es una producción de la Unidad Ejecutora INCUAPA-CONICET (Instituto de Investigaciones Arqueológicas y Paleontológicas del Cuaternario Pampeano) dirigido por el Dr. Gustavo Politis. Las opiniones vertidas en el presente trabajo son de nuestra absoluta responsabilidad. 


\section{Referencias citadas}

"Álvarez, M. (2003). Organización tecnológica en el canal de Beagle. El caso de Túnel 1 (Tierra del Fuego, Argentina). (Tesis Doctoral inédita), Universidad de Buenos Aires, Argentina.

» Aschero, C. A. (1975). Ensayo para una clasificación morfológica de artefactos líticos aplicada a estudios tipológicos comparativos. Informe al CONICET. Manuscrito inédito.

» Aschero, C. A. (1983). Ensayo para una clasificación morfológica de artefactos líticos aplicada a estudios tipológicos comparativos. Apéndices A-C. Manuscrito inédito.

»Aschero, C. A. y Hocsman, S. (2004). Revisando cuestiones tipológicas en torno a la clasificación de artefactos bifaciales. En M. Ramos, A. Acosta y D. Loponte (Eds.), Temas de Arqueología. Análisis Lítico (pp. 7-26). Luján: Universidad Nacional de Luján.

» Aschero, C. A., Manzi, L. M. y Gómez, A. G. (1993-1994). Producción de recursos líticos y uso del espacio en el nivel 2b4 de Quebrada Seca 3. Relaciones de la Sociedad Argentina de Antropología, XIX, 191-214.

» Bayón, C., Flegenheimer, N., Valente, M. y Pupio, A. (1999). Dime cómo eres y te diré de dónde vienes: La procedencia de rocas cuarcíticas en la región pampeana. Relaciones de la Sociedad Argentina de Antropología, XXIV, 187-235.

» Bayón, C., Flegenheimer, N. y Pupio, A. (2006). Planes sociales en el abastecimiento y traslado de roca en la Pampa Bonaerense en el Holoceno temprano y tardío. Relaciones de la Sociedad Argentina de Antropología, XXXI, 19-45.

» Bellelli, C., Guráieb, G. y García, J. (1985-1987). Propuesta para el análisis y procesamiento por computadora de desechos de talla lítica (DELCO - Desechos líticos computarizados). Arqueología Contemporánea, 2(1), 36-53.

»Berón, M. A. (2006). Base regional de recursos minerales en el occidente pampeano. Procedencia y estrategias de aprovisionamiento. Relaciones de la Sociedad Argentina de Antropología, XXXI, 47-88.

» Beyries, S. y Rots, V. (2008). The contribution of ethno-archaeological macro and microscopic wear traces to the understanding of archaeological hide-working processes. En L. Longo y N. Skakun (Eds.), Prehistoric Technology 40 years later: Functional Studies and the Russian Legacy (pp. 21-28). Oxford: BAR International Series 1783.

"Binford, L. (1980). Willow smoke and dogs tails: Hunter-gatherer settlements systems and archaeological site formation. American Antiquity, 45, 4-20.

" Bonomo, M. (2005). Costeando las Llanuras. Arqueología del Litoral Marítimo Pampeano. Buenos Aires: Sociedad Argentina de Antropología.

» Bórmida, M. (1960). Investigaciones paletnológicas en la Región de Bolívar, Provincia de Buenos Aires. Anales de la Comisión de Investigaciones Científicas de la Provincia de Buenos Aires, 1, 190-283.

» Bórmida, M. (s/f). Prolegómenos para una arqueología de la Pampa Bonaerense. Edición oficial de la Provincia de Buenos Aires. La Plata: Dirección de Bibliotecas, Museos y Archivos Históricos.

" Carrera Aizpitarte, M. P., Berón, M. A. y Blasi, A. (2015). Study of siliceous outcrops of Meseta del Fresco, La Pampa, Argentina. Quaternary International, 375, 27-43. 
"Catella, L., Moirano, J. y Oliva, F. (2010). Disponibilidad de materias primas líticas y su importancia para el análisis del uso del espacio y la organización de la tecnología en sociedades cazadoras recolectoras. En M. A. Berón, L. Luna, M. Bonomo, C. Montalvo, C. Aranda y M. Carrera Aizpitarte (Eds.), Mamul Mapü: Pasado y Presente desde la arqueología pampeana (Volumen II, pp. 239-254). Buenos Aires: Libros del Espinillo.

»Cingolani, C. A. (2005). Unidades morfoestructurales (y estructuras menores) de la provincia de Buenos Aires. En R. R. de Barrio, R. O. Etcheverry, M. F. Caballé y E. Llambías (Eds.), Relatorio XVI Congreso Geológico Argentino. Geología y Recursos Minerales de la Provincia de Buenos Aires (pp. 21-30). La Plata: Asociación Geológica Argentina.

»Colombo, M. (2011). Modalidades de abastecimiento de rocas entre los cazadores y recolectores pampeanos. Intersecciones en Antropología, 12, 231-243.

» Iriondo, M. (1999). Climatic changes in the South American plains: Records of a continentscale oscillation. Quaternary International, 57-58, 93-112.

»Keeley, L. (1980). Experimental Determination of Stone Tool Uses: A Microwear Analysis. Chicago: University of Chicago Press.

»Kononenco, N. (2011). Experimental and archaeological studies of use-wear and residues on obsidian artefacts from Papua New Guinea. Technical Reports of the Australian Museum, 21, 1-244.

» Kruck, W., Helms, F., Geyh, M. A., Suriano, J. M., Marengo, H. G. y Pereyra, F. (2011). Late Pleistocene-Holocene history of Chaco-Pampa sediments in Argentina and Paraguay. Quaternary Science Journal, 6o(1), 188-202.

»Leipus, M. (2016). Variabilidad tecnomorfológica y funcional de las raederas en la Región Pampeana (Argentina). Revista de Antropología del Museo de Entre Ríos, 2(2), 47-67.

» Leipus, M. y Mansur, M. E. (2007). El análisis funcional de base microscópica aplicado a materiales heterogéneos. Perspectivas metodológicas para el estudio de las cuarcitas de la Región Pampeana. En C. Bayón, A. Pupio, M. I. González, N. Flegenheimer y M. Frère (Eds.), Arqueología en las Pampas (Tomo I, pp. 179-200). Buenos Aires: Sociedad Argentina de Antropología.

» Lemonnier, P. (1976). La description des chaines opératoires: contribution a l'analyse des systemes techniques. Techniques et Culture, 1, 101-150.

» Lemorini, C., Stiner, M., Gopher, A., Shimelmitz, R. y Barkai, R. (2006). Use-wear analysis of an Amudian laminar assemblage from the Acheuleo-Yabrudian of Qesem Cave, Israel. Journal of Archaeological Science, 33, 921-934.

»León, R. J. C. (1991). Vegetación. En R. T. Coupland (Ed.), Natural Grasslands. Introduction and Western Hemisphere, Ecosystems of the World 8A (pp. 380-387). Nueva York: Elsevier.

" Madrazo, G. B. (1973). Síntesis de arqueología Pampeana. Etnía, 17, 13-25.

" Malagnino, E. C. (1989). Paleoformas de origen eólico y sus relaciones con los modelos de inundación de la provincia de Buenos Aires. Actas del IV Simposio Latinoamericano de Percepción Remota y IX Reunión Plenaria Selper (Tomo II, pp. 611-620). Bariloche.

» Mansur, M. E. (1999). Análisis funcional de instrumental lítico: Problemas de formación y deformación de rastros de uso. Actas del XII Congreso Nacional de Arqueología Argentina, (pp. 355-366). La Plata.

» Mansur-Franchomme, M. E. (1986-1990). Instrumentos líticos: Aspectos da análise funcional. Arquivos do Museu de Historia Natural, 11, 115-169.

» Messineo, P. G. y Barros, M. P. (2015). Lithic raw materials and modes of exploitation in quarries and workshops from the center of the Pampean grassland of Argentina. Lithic Technology, 40(1), 3-20. 
» Messineo, P. G., González, M. E., Álvarez, M. C. y Pal, N. (2018). Las ocupaciones humanas en la localidad arqueológica Laguna de los Pampas (Campo de Dunas del Centro Pampeano, Argentina) durante el Holoceno. Latin American Antiquity, 29(4), 736-753.

» Messineo, P. G. y Scheifler, N. A. (2016). Investigaciones arqueológicas en el sitio Laguna Cabeza de Buey 2 (San Carlos de Bolívar, Buenos Aires). Cincuenta años después de las Industrias Culturales definidas por Bórmida. Intersecciones en Antropología, 17, 213-227.

» Messineo, P. G., Tonello, M.S., Stutz, S., Tripaldi, A., Scheifler, N., Pal, N., Sánchez Vuichard, G. y Navarro, D. (2019). Human occupations strategies and related environment-climate during the Middle and Late Holocene in central Pampas of Argentina. The Holocene, 29(2): 244-261.

»Oliva, F. y Moirano, J. (1997). Primer informe sobre aprovisionamiento primario de riolita en Sierra de la Ventana (provincia de Buenos Aires, Argentina). En M. A. Berón y G. G. Politis (Eds.), Arqueología Pampeana en la Década de los '9o (pp. 137-146). Mendoza: Museo de Historia Natural de San Rafael e Investigaciones Arqueológicas y Paleontológicas del Cuaternario (UNCPBA).

»Pal, N. (2012). Tendencias temporales en las estrategias de explotación y uso de los materiales líticos de la cuenca superior del arroyo Tapalqué (Partidos de Benito Juárez y Olavarría): Una perspectiva desde el Análisis Funcional. (Tesis Doctoral inédita), Universidad Nacional del Centro de la provincia de Buenos Aires, Argentina.

»Pal, N. (2013). Diseños y usos de los artefactos líticos manufacturados por cazadoresrecolectores en la cuenca superior del Arroyo Tapalqué (provincia de Buenos Aires). Comechingonia. Revista de Arqueología, 17, 171-187.

»Pal, N. (2015). Estrategias de uso de instrumentos líticos en la cuenca superior del arroyo Tapalqué durante el Holoceno tardío (Provincia de Buenos Aires). Intersecciones en Antropología, 16, 53-68.

»Pfaffenberger, B. (1988). Fetishised objects and humanised nature: Towards an anthropology of technology. Man, 23(2), 236-252.

»Politis, G. G. (2007). Nukak. Etnoarchaeology of an Amazonian People. California: Left Coast Press.

» Rots, V. (2012). What method to study hafting? The potential of use-wear and residue analysis confronted. En C. Lemorini y S. N. Cesaro (Eds.), An Integration of the Use-Wear and Residue Analysis for the Identification of the Function of Archaeological Stone Tools (pp. 27-42). Oxford: BAR International Series 2649.

»Scheifler, N. A. (2018). Estudio zooarqueológico de la subsistencia de los cazadoresrecolectores en el área Oeste de la subregión Pampa Húmeda durante el Holoceno medio y tardío. (Tesis Doctoral inédita), Universidad Nacional del Centro de la provincia de Buenos Aires, Argentina.

»Scheifler, N. A. y Messineo, P. G. (2016). Exploitation of faunal resources by huntergatherers in the center of the pampa grasslands during the Holocene. An approach through the study of the archaeofauna of the Laguna Cabeza de Buey 2 site (San Carlos de Bolivar, Buenos Aires, Argentina). Quaternary International, 391, 61-73.

»Scheifler, N. A., Messineo, P. G. y Antiñir, A. (2017). Cazadores-recolectores en el sistema lagunar Hinojo-Las Tunas (región pampeana, área Oeste) durante la transición Holoceno temprano-medio y tardío. Primeros resultados de las investigaciones arqueológicas. Comechingonia. Revista de Arqueología, 21(1), 287-314.

» Tonello, M., Messineo, P. G., Stutz, S., Scheifler, N. A. y Sánchez Vuichard, G. (2015). La historia paleoambiental de la llanura pampeana desde una perspectiva integradora. Resúmenes de la Reunión de Comunicaciones de la Asociación Paleontológica Argentina (RCAPA 2015), p. 51. Mar del Plata. 
» Tripaldi, A., Alonso, M. S., Messineo, P. G. y Salvo Bernárdez, S. C. (2018). Composición petrográfica y proveniencia de arenas eólicas de las dunas de la Pampa central, Argentina: resultados preliminares. Resúmenes del Séptimo Congreso Argentino de Cuaternario y Geomorfología. Naturalia Patagónica, 10, 342-343.

"Vecchi, R. (2016). Materias primas líticas de bolas de boleadora del sector bonaerense de la región Pampeana. Relaciones de la Sociedad Argentina de Antropología, XLI (1), 191-215.

»Zárate, M. A. y Tripaldi, A. (2012). The aeolian system of central Argentina. Aeolian Research, 3, 401-417. 